
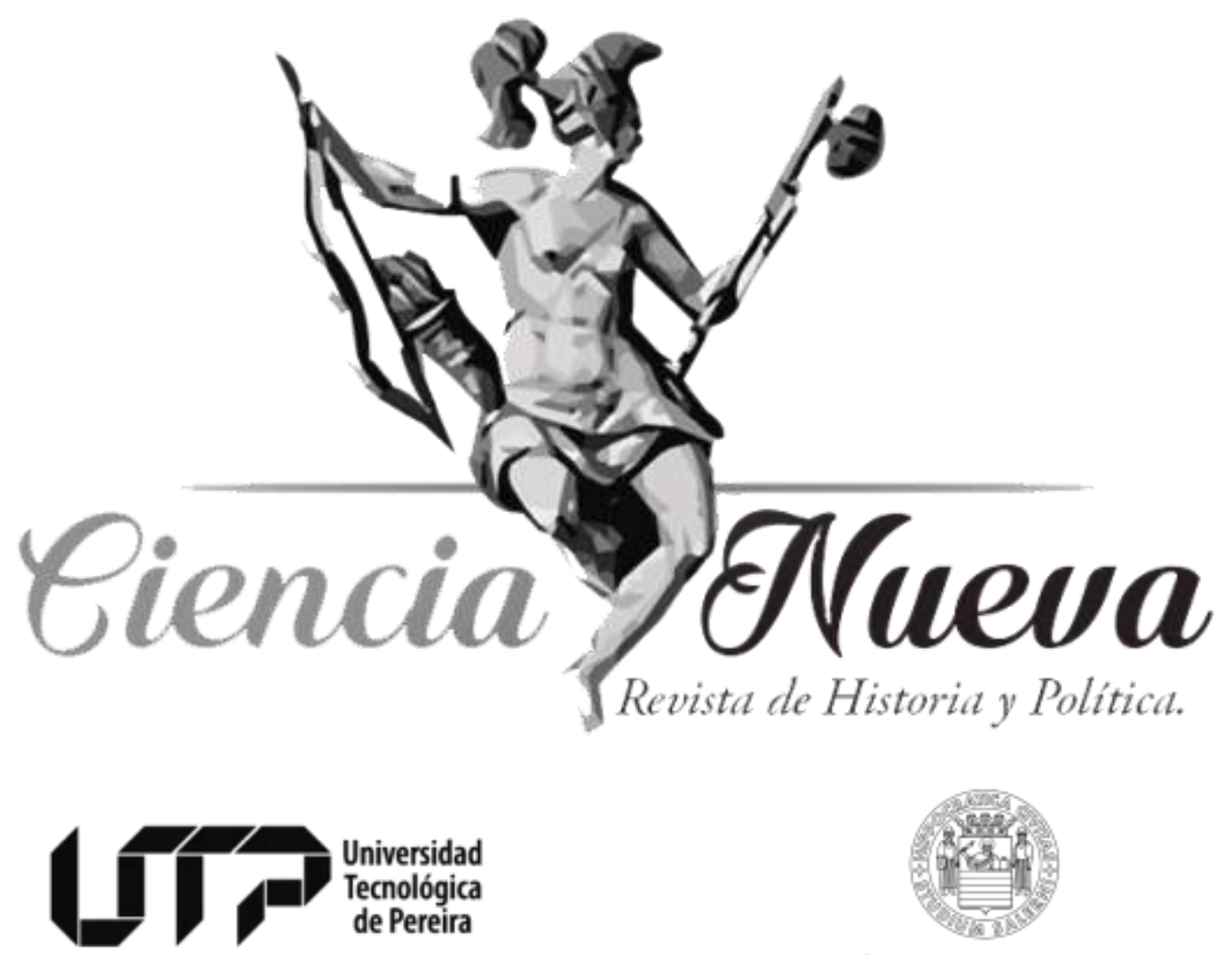

UNIVERSITÀ DEGLI STUDI DI SALERNO

Maestría en Historia

Maestría en Ciencia Política

ANALES Y MEMORIAS DEL CENTRO-OCCIDENTE COLOMBIANO

SERIE DE 12 ESCRITURAS PÚBLICAS QUE VINCULA A LOS VECINOS DE PUERTO VIEJO CON LOS DE LIMA Y CUZCO (1535-1601) EN LOS REGISTROS DEL ARCHIVO GENERAL DE LA NACIÓN DEL PERÚ SERIES OF 12 PUBLIC SCRIPTURES OF THE REGISTERS OF NATIONAL ARCHIVE OF PERÚ, THAT LINKS THE INHABITANTS OF PUERTO VIEJO WITH THEIR NEIGHBORS OF LIMA AND

CUZCO (1535-1601)

DOI: https://doi.org/10.22517/25392662.19071

Jodison Javier García Alcívar y Elena Anyeline Torres Cedeño

pp. 222-251

Vol. 3 Núm. 1 | Enero-Junio de 2019

Pereira, Colombia 


\section{SERIE DE 12 ESCRITURAS PÚBLICAS QUE VINCULA A LOS VECINOS DE PUERTO VIEJO CON LOS DE LIMA Y CUZCO (1535-1601) EN LOS REGISTROS DEL ARCHIVO GENERAL DE LA NACIÓN DEL PERÚ*}

\section{SERIES OF 12 PUBLIC SCRIPTURES OF THE REGISTERS OF NATIONAL ARCHIVE OF PERÚ, THAT LINKS THE INHABITANTS OF PUERTO VIEJO WITH THEIR NEIGHBORS OF LIMA AND CUZCO (1535-1601)}

Jodison Javier García Alcívar ${ }^{* *}$

jodgarcia@uees.edu.ec

ORCID: http://orcid.org/0000-0001-9582-5475

Elena Anyeline Torres Cedeño***

anyelinetorres@ hotmail.com

ORCID: http://orcid.org/0000-0001-9429-9979

$\begin{aligned} \text { Recibido: } & \text { 24 de agosto de } 2018 . \\ \text { Revisado: } & 12 \text { de febrero de } 2019 . \\ \text { Aceptado: } & 03 \text { de mayo de } 2019 . \\ \text { Publicado: } & 30 \text { de junio de } 2019 .\end{aligned}$

\section{Análisis introductorio}

7 engo a bien aceptar este reto de un dueto académico evolutivo. Así como los músicos, intérpretes y cantantes armonizan sus acompañados cuartetos y quintetos, admito la gala del incesante investigar en el 2018 del siglo XXI, en el que se da tocante la acuciosa tarea de escribir. Claro está, es sinónimo de teclear o pulsar botones en los ordenadores, porque a esta fecha, la escritura ha transitado de lo manuscrito y desde las maquinadas tipografías escribientes a cómodos y acelerados pulsos de dactilares presiones, por su hoy aleatoriedad y lectura, basado todo ello, en el movimiento dominante de ambos carpos cómplices.

Los siguientes 12 documentos transcritos letra a letra, forman parte de un compendio de manuscritos registrados y conservados en el Archivo General de la Nación del Perú (AGN), que el paleógrafo Javier García Alcívar consultó y encontró, durante su breve estancia en Lima en 2009, una vez que pretendía cursar la Licenciatura en Humanidades o en Historia en la Universidad Nacional Mayor de San Marcos (UNMSM) cuando aún era

\footnotetext{
* Esta transcripción respeta las directrices y normas dispuestas en la Declaración de Ética de Publicación de Ciencia Nueva, Revista de Historia y Política. Esta declaración puede consultarse en la página web de la revista: revistas.utp.edu.co/index.php/historia.

** Autor de la transcripción. Licenciado en Historia del Arte y magíster en Dirección del Talento Humano por la Universidad de Especialidades Espíritu Santo (UEES) de Samborondón, Ecuador. Candidato a magíster en Industrias Culturales y Creativas por la Universidad Europea Miguel de Cervantes (UEMC) de Valladolid, España. Paleógrafo e Historiador de los siglos XVI, XVII Y XVIII.

*** Análisis de la transcripción. Ingeniera en Contabilidad y Auditoría y licenciada en Educación Primaria por la Universidad Laica Eloy Alfaro de Manabí (ULEAM), Ecuador. Magíster en Formación Internacional Especializada del Profesorado por la Universidad Complutense de Madrid (UCM), España. Docente del Ministerio de Educación en Manta, Ecuador. Asambleísta alterna de la República por Manabí.
} 
Bachiller. Para entonces, suspendió su transcripción por no poderlos descifrar. Ya como estudiante universitario, desde 2011, anduvo el largo camino de aprendizaje, que iría adquiriendo con el transcurrir de los años en los temas del patrimonio manuscrito. Se tiene presteza de miramiento en admitir la confianza que deposita el paleógrafo en la seriedad de quien le preludie y prologue sus transcripciones y lo que supone, además, la no tan fácil labor de analizar registros históricos, que fueran hasta la fecha desconocidos y de canalizada frescura cognoscitiva. Tengo la entera certeza de que vendrán otros duetos académicos como este, que con su transcurrir se harán libros de valioso acrecentamiento a la lectura histórica ecuatoriana e iberoamericana.

Estos registros notariales tratan la cotidianidad y la mentalidad de los siglos XVI y XVII en territorio peruano a la manera de la Corte de Madrid $^{1}$, transmiten los pactos y consentimientos de personas que están relacionadas con los personajes históricos directa e indirectamente vinculantes con la actual provincia ecuatoriana de Manabí. La importancia de esta docena de documentos es la consecuencia prolífica y la intención acuciosa del paleógrafo al haber publicado y con ello revelado la asombrosa disponibilidad del libro Registros escribaniles de la Tenencia de Puerto Viejo ${ }^{2}$, el 24 de agosto de 2017 en el portal web Amazon.com. Texto prologado en substancia y analizado historiográficamente esa vez por el Lcdo. Eudoro Fabricio Solórzano Zambrano, quien fuera su editor. El hecho significó un logro bibliográfico enriquecedor para la historiografía ecuatoriana, aplaudido banquete de datos e información fidedigna que ha sido capaz de complacer las más desconocidas pistas de quienes, dónde, cómo y cuándo acontecieron episodios desconocidos ante el variopinto rompecabezas de quehaceres que significa todavía construir paso a paso el periodo colonial (1535-1820). Periodo que abarcó el territorio y jurisdicción de la Tenencia de Puerto Viejo y es el equivalente jurídico de la hoy Provincia de Manabí, ubicada en el litoral del Ecuador continental.

En definitiva, para analizar pedagógicamente la magnífica revelación de estos documentos que siguen, se advierte de la evolución de la escritura pública o de la fe pública notarial, desde el punto de vista cronológico proveniente de la Historia del Arte, que señala y ubica el contexto de esta producción documental, sitiándolas en el Renacimiento intermedio y tardío (1530-1600), así como en el Barroco temprano (1601-1650)³. Desde la noción historiográfica europea corresponde, según Bartolomé Benassar, al Siglo de Oro español (1492-1681), los 189 años marcados por el apogeo artístico, científico, cultural, literario y hegemónico político de España en el mundo, durante los reinados de la dinastía Habsburgo: Carlos I (1516-1556), Felipe II (1556-1598), Felipe III (1598-1621), Felipe IV (1621-1665), la regencia de Mariana de Austria (1665-1675) y Carlos II (1665-1700), o hasta la muerte del escritor Calderón de la Barca en $1681^{4}$. Desde el punto de vista historiográfico

\footnotetext{
${ }^{1}$ Ignacio Lozón Urueña, Madrid Capital y Corte. Usos, costumbres y mentalidades en el siglo XVII (Madrid, España: Consejería de Educación Comunidad de Madrid, 2004).

${ }^{2}$ Jodison Javier García Alcívar, Registros escribaniles de la Tenencia de Puerto Viejo. Ed. por E. F. Solorzano Zambrano (Portoviejo, Manabí, Ecuador: Amazon Kindle Publishing, 2017).

${ }^{3}$ Ernst H. Gombrich, La Historia del Arte. Decimosexta edición (Londres, Reino Unido: Phaidon Press Limited, 2010).

${ }^{4}$ Bartolomé Bennassar, La España del Siglo de Oro. Trad. por P. Bordonava (Barcelona, Cataluña, España: Editorial Crítica, 1983).
} 
latinoamericano, el periodo que cubre a las escrituras corresponde a la época colonial o de dominación española, el momento de la suscripción escribanil ${ }^{5}$.

Las letras descifradas de acuerdo a su ortografía manuscrita mediante la técnica paleográfica son las siguientes. a) Las que abarcan el siglo XVI son: la letra procesal, la letra encadenada o redonda y la letra cortesana. b) La ortografía del siglo XVII únicamente distinguida es la letra procesal. Estas categorizaciones manuscritas han sido anteriormente propuestas por el paleógrafo, aquí autor ${ }^{6}$, en base al Manual de Paleografía ${ }^{7}$ y otras guías y tratados de su categoría ${ }^{8}$. Los compromisos económicos adquiridos en las empresas de conquista demuestran la creciente aparición de intereses políticos y económicos emanados del seno de los nacientes cabildos americanos.

En mi análisis destaco preludiar los fragmentos escriturarios que proveen mayor información histórica. En el caso que nos concierne despejar, con miras al contenido del texto histórico, en el documento 1 el célebre capitán Francisco de Orellana, adeuda a Pedro Sánchez de Ortega 3900 pesos de oro, por la compra de siete caballos, dos esclavos negros y otros objetos, en 1533. Por lo cual, vencido el plazo de cuatro años, determina que se cobren de sus bienes muebles, raíces y tributos a él debidos en la Villa Nueva de Puerto Viejo, mientras este se encontraba de viaje por la urgente convocatoria que le hizo el gobernador Francisco Pizarro para irse a la Guerra del Cuzco o Sitio del Cuzco (1536-1537). Sabremos así que de Orellana sí estuvo allí. De Orellana se vuelve a mencionar en el documento 3 con la misma calidad de deudor, le compra al capitán Hernando de Bachicao dos caballos y un esclavo negro en 2000 pesos de oro, con la prohibición de enajenación durante el plazo a pagar de seis meses. De Orellana fue implacable e incansable conquistador, inclinado arriesgadamente a la fama, la política militar y la cosa bélica. Esto acaeció, una vez culminado el conflicto del Cerco del Cuzco desde el 18.04.1537.

En el documento 2, quien fuera el pacificador y fundador de la Villa Nueva de Puerto Viejo en 1535, el capitán Francisco Pacheco, encontrándose en Lima el 06.12.1537, presta a Francisco Milanés 100 pesos de oro, que se obliga a devolverlos en veinte días a su vuelta de Nicaragua, y en caso de que no suceda se lo cobre en la Gobernación de Nicaragua. Este documento confirma el temprano retiro de Pacheco de la Gobernación de Nueva Castilla, sospechosamente de forma temporal debido a la poca cantidad prestada, siendo pública y notoria la hazaña que lo había hecho famoso: poner al yugo de Castilla a treinta caciques de Puerto Viejo ${ }^{9}$. El prestigio de Pacheco había elevado su confianza hasta para contraer deudas en el largo plazo y a distancias dilatadas. En el documento 4, Alonso Guerrero, encontrándose en Lima el 07.06.1538, otorga poder a Alonso Bolaños para que en la Villa Nueva de Puerto Viejo cobre al teniente de gobernador capitán Gonzalo de Olmos y al vecino Baltasar García, 140 pesos de oro.

\footnotetext{
${ }^{5}$ Fernando Bellver Amaré, La creación de un mundo. Hispanoamérica (Madrid, España: Machado Grupo de Distribución, 2014).

${ }^{6}$ Jodison Javier García Alcívar, Mecanismos básicos para investigar el patrimonio documental manuscrito en plataformas en línea (Instituto Nacional de Patrimonio Cultural, Portoviejo: Sistema de Gestión Documental Quipux, 2017).

${ }^{7}$ María Mercedes Ladrón de Guevara, Manual de Paleografía (Bogotá, Colombia: Centro Editorial Javeriano, 1996).

${ }^{8}$ Jorge A. Garcés Garcés, Paleografía diplomática española y sus peculiaridades en América (Quito, Pichincha, Ecuador: Editorial Casa de la Cultura Ecuatoriana, 1960).

${ }^{9}$ Octavio Latorre T, Thomás de Berlanga y de descubrimiento de Galápagos (Quito, Pichincha, Ecuador: Artes Gráficas Señal, Impreseñal Cía. Ltda., 1996).
} 
En el documento 5, Jerónimo de Aliaga, vecino de Lima, el 16.07.1538 autoriza a Bartolomé Pérez, vecino de Puerto Viejo, para que cobre todos los dineros a él debidos o sus equivalencias en pesos de oro, ducados, plata, joyas, caballos, ganados porcinos o bovinos, esclavos negros e indios. Bartolomé Pérez vuelve a aparecer el 30.07 .1538 en el documento 6, con Juan de Olmos, como vecinos de Puerto Viejo, junto a Rodrigo Marcheno, quienes, a nombre de Francisco de Chávez, teniente de gobernador de la Ciudad de los Reyes, cobrasen las deudas a él debidas en la Villa Nueva de Puerto Viejo, ya sea en dineros, o con los mismos bienes muebles de alto precio equivalentes, que eran los de calidad, anteriormente enumerados.

En el documento 07, Cristóbal de Ayala, vecino de Puerto Viejo, estando en Cuzco se ocupa de comprar un caballo color castaño, ensillado, entrenado y bien aderezado a Juan del Valle vecino de Cuzco, por 1500 pesos de oro.

Los documentos 09, 10 y 11, nos aclaran el panorama padecido por la condición de indio, contratado o "concertado" para cumplir actividades económicas específicas relacionadas con servicios no aclarados y actividades agrícolas. Aparte de la paga anual, para el interesado era obligatorio dotar al indio de indumentaria de algodón, curarle sus enfermedades, alimentarle tres veces al día, darle tiempo para aprender la doctrina cristiana y asistir a misa. La particularidad interesante de estas escrituras es que dan cuenta de la procedencia de los indios, que hablan del concepto Puerto Viejo como una comarca, que abarcaba no solo la ciudad, sino su dominio político sobre otros pueblos en su contorno.

El asunto del documento 12 es cotidiano y cubierto de solemnidad con solvencia financiera mutua, ya que, simbólicamente, la parte que le concernía a la esposa pasaba a ser administrada por manos del esposo. Se trata de una dote de 1000 pesos de plata, transferida por motivo del matrimonio de doña Juana de Solórzano, hija de Juan de Santa Cruz de Solórzano y María Ruiz, vecinos de Puerto Viejo. El prometido era Domingo Martín, oriundo de la Villanueva del Algarve en Portugal, quien sumaba a la dote, la "donación entre libros" de otros 1000 pesos, el total de aquella cantidad ascendió a un monto líquido de caudal patrimonial de 2000 pesos de plata.

Finalmente, son documentos que por su tipo inscriben formulismos (contenido textual integral) y formalismos (contexto histórico legal) escribaniles, es decir, formulas literales jurídicas oficiales que justificaban un acto, hecho o acuerdo, adoptados por el escribano público, funcionario antecesor del notario público ecuatoriano de hoy. De hecho, dichos formulismos estaban ligados a regular la manera de escribir, cuya interpretación textual eficaz, asegura, en el momento global del 2018, el fomento estratégico de sublimar y exaltar la memoria colectiva de cómo eran los ciudadanos viandantes. También podemos reivindicarnos en nosotros mismos, interpelar el texto histórico para fines multidisciplinares científicos, de tales o cuales ingentes aprovechamientos. El valor académico de esta documentación manuscrita sirve y servirá para ampliar el conocimiento en las humanidades y en las categorizaciones que emanan de la historia, como la economía, la política, la sociología, la antropología, la filosofía y sucesivamente vastos etcéteras. 
Tabla 1. Aspectos que la escritura pública es capaz de explicar en el texto histórico.

\begin{tabular}{|l|l|}
\hline Mensaje emisor & Significantes históricos \\
\hline Data biográfica & $\begin{array}{l}\text { ¿Qué hacía el firmante o los firmantes en ese momento de su } \\
\text { vida? ¿Quién o quiénes eran los funcionarios fedatarios y } \\
\text { testigos? Este aspecto explica las razones sociales, económicas, } \\
\text { morales y psicológicas de los individuos habilitados. }\end{array}$ \\
\hline Data cronológica & $\begin{array}{l}\text { ¿Cuál era el lugar y la fecha de su inscripción en el registro de } \\
\text { su producción? Se explica la procedencia de los suscribientes. }\end{array}$ \\
\hline Contexto político & $\begin{array}{l}\text { ¿Quiénes eran las autoridades locales en el momento de la } \\
\text { suscripción del documento? }\end{array}$ \\
\hline Contexto jurídico & $\begin{array}{l}\text { ¿Cómo estaban concebidos los tipos de actos en categorías } \\
\text { jurídicas según su asunto de un siglo a otro? ¿Cuál era la } \\
\text { doctrina jurídica en el contexto de la producción escrituraria? }\end{array}$ \\
\hline Mensaje escribanil & $\begin{array}{l}\text { Los escribanos, amanuenses y escribientes son capaces de } \\
\text { narrar y describir objetos, personas, circunstancias y lugares, } \\
\text { con adjetivos calificativos en el momento de la suscripción de } \\
\text { la escritura. Lo cual transmite aspectos desconocidos de la vida } \\
\text { cotidiana. Se trata de un mensaje escrito "entre líneas" que } \\
\text { afirma, niega, o acepta un acontecimiento implicado en el acto } \\
\text { escriturario. }\end{array}$ \\
\hline
\end{tabular}

Fuente: Jodison Javier García Alcívar, Mecanismos básicos para investigar el patrimonio documental manuscrito en plataformas en línea (Instituto Nacional de Patrimonio Cultural Portoviejo: Sistema de Gestión Documental Quipux, 2017).

\section{Notificación paleográfica}

(a): Texto adicional agregado por el autor para completar una palabra u oración.

d?: Palabra o letra de dudosa interpretación paleográfica.

...: Espacios incompletos de numeración y codificación que no se pueden descifrar por pérdida o desintegración del soporte documental material y gráfico.

(f): Firma o signado de un nombre propio.

//: Fragmento de renglón desaparecido. 
Documento 1.- CARTa de Obligación de PAgo por mayor CuANTía del CAPITÁn Francisco de Orellana vecino de Puerto Viejo a Pedro Sanchez Ortega maestre DEL NAVÍO NOMBRAdo "SAN JUAN" EN LA CANTIDAD DE 3900 PESOS DE BUEN ORO, POR HABERSELE VENDIDO EN 1533 SIETE CABALLOS, DOS NEGROS Y OTRAS COSAS, QUE ORELLANA

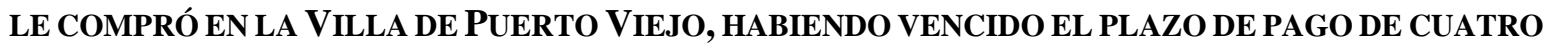
AÑOS A LA FECHA, LO CUAL SE COBRE EN PUERTO VIEJO POR AUTOS SU EQUIVALENCIA DE SUS HACIENDAS, GRANJERIAS, 200 PUERCOS Y OTRAS COSAS, DEBIDO A LA URGENCIA QUE TIENE ORELlANA DE IR A LA GUERRA DEL CUZCO EN COMPAÑía DEL GOBERNADOR FRANCISCO PiZARro (Lima, Gobernación de Nueva Castilla 08.06.1537).

$/{ }^{10}$ Obligaçión.- Sepan quantos esta carta vieren como yo, el Capitán Françisco de Orellana Veçino de la Villa de Villa Nueva de Puerto Viejo estante al presente en esta Çiudad de los Reyes otorgo e conozco e digo que por quanto Pedro Sanches de Ortega que soys presente Maestre del Navío nombrado San Juan que (me) vendistes en la dicha Villa syete cavallos y dos negros e otras cosas por coantía de tres myll e noveçientos pesos de buen oro de a razón de a quatro años e (cin)quenta maravedís cada peso, y dellos me heziste una obligaçion ante Pedro Che? ${ }^{11}$ Escryvano de Sus Magestades el plazo de la qual es ya pasado, o se cumple, e como quyera que vos el dicho Pedro Sanches me pudierades executar por la dicha coantía, lo qual haciendo, yo resciviera muy gran daño y pérdida de my hazienda y desaviamyento ${ }^{12}$ del presente viaje que voy en seguymyento del Señor Governador don Françisco Piçarro a la guerra del Cuzco, e vos por me hazer plazer e buena obra no lo hazeys al presente, por ende otorgo e conozco, digo que soy contento y he por bien que vay(a)s a la dicha Villa de Puerto Viejo donde soy Vezino y tengo my hazienda e resçibays y ayays y cobreys toda la dicha deuda de todas mys haziendas e granjerías asy de dozientos y tantos puercos, e lo mas triplicado que al presente allá tengo ${ }^{13}$, e de todo el pryvileyo ${ }^{14}$ e tributo que al presente tengo cogido e cogiere la persona que por my, y en my nonbre resçiba e cobre e resçibiere e cobrare, e de todos los más bienes e casas y otras cosas que yo tengo, e sino ovieredes libremente la dicha coantía, podays executar la dicha obligaçión en todo lo que dicho es, y espeçialmente en los dichos vuestros cavallos, ésto no ynovando cosa alguna en la dicha primera obligaçion, antes añadiendo fuerça a fuerça e cabo a cabo, e quedando en su fuerça e vigor la dicha primer escriptura, otorgo e me obligo de aver por firme, todo lo que dicho es, so pena del doblo, para lo/ ${ }^{15}$ qual obligo my persona e bienes rayzes e muebles avidos e por aver so la dicha ypoteca y éstos dichos pesos de oro se entiende que an de ser, no del oro que fundió guarden, sino de buen oro e mynas de ley, por falta que valga cada un peso quatroçientos e çinquenta maravedís de buena moneda; e por esta carta doy e otorgo mi poder cumplido a todas e qualesquier Justiçias de Sus Magestades e de la dicha Villa Nueva e de otras provynçias destos Reynos del Perú para que pedido rigor de derecho me conttenga e apremye a lo asy mandado de presente ha sido entrega (a) execuçión en los dichos puercos e otros héneros e tributos de suso adelantados, e en todos mys bienes los vendiesen?, e rema(nentes) an de dar por autos, vos entreguen e signaredes de prinçipal e costas al thenor e firma de la dicha obligaçión e renunçio a las (justicias) destas partes e qualesquier leyes, fueros e derechos que en my favor sean, para poder venyr

\footnotetext{
${ }^{10}$ Archivo General de la Nación del Perú, Signatura: N_1_PAC1_0,513_330-330v_0825, Folio 330.

11 ¿Sería Pedro de Salinas?, quien fuera escribano del Cabildo de Lima. El escribano o el escribiente comete claramente un error al pasar la escritura de borrador a limpio, la mención de una escritura de referencia, otorgada en la misma Ciudad de Lima hacia 1535.

12 De desavío: des y avío. Como sinónimo de desventaja o desbeneficio.

${ }^{13}$ El capitán Francisco de Orellana menciona que su hacienda o caudal personal ascendía en equivalentes bienes a la fecha, en la cantidad que él debe en esta carta multiplicada por tres, es decir, 3900 pesos de buen oro x $3=$ 11700 pesos de buen oro. Lo que, hasta entonces, lo convertía en uno de los hombres más solventes en el noroeste de toda la Gobernación de Nueva Castilla.

${ }^{14}$ Anótese la necesidad de aprender a descifrar la forma de abreviar esta palabra que se puede confundir con palabras como syrvycio o dinero, para este tipo de escrituras.

${ }^{15}$ Archivo General de la Nación del Perú, Signatura: N_1_PAC1_0,513_330-330v_0826, Folio vuelta 331.
} 
en contra lo que dicho es que no valdrá, e espeçialmente renunçio la ley e Regla de derecho en que diz que general renunciaçión, non violará my fyrmeza de lo qual otorgué esta carta ante Escryvano e supe de yuso escryptos, e lo fyrmé de my nonbre en el Registro desta carta.

Ques fecha e otorgada en la Çiudad de los Reyes, ocho días del mes de Junyo año de myll e quynyentos e treynta e siete años, siendo testigos el Bachiller Myguel Rodríguez de Cantalopredia e Antonyo de Navarrete Escryvano de Sus Magestades e Xpoval Piçarro estantes en esta Çiudad. (f) Françisco de Orellana. Ante my; (f) Antonyo de Olivares. Escryvano.

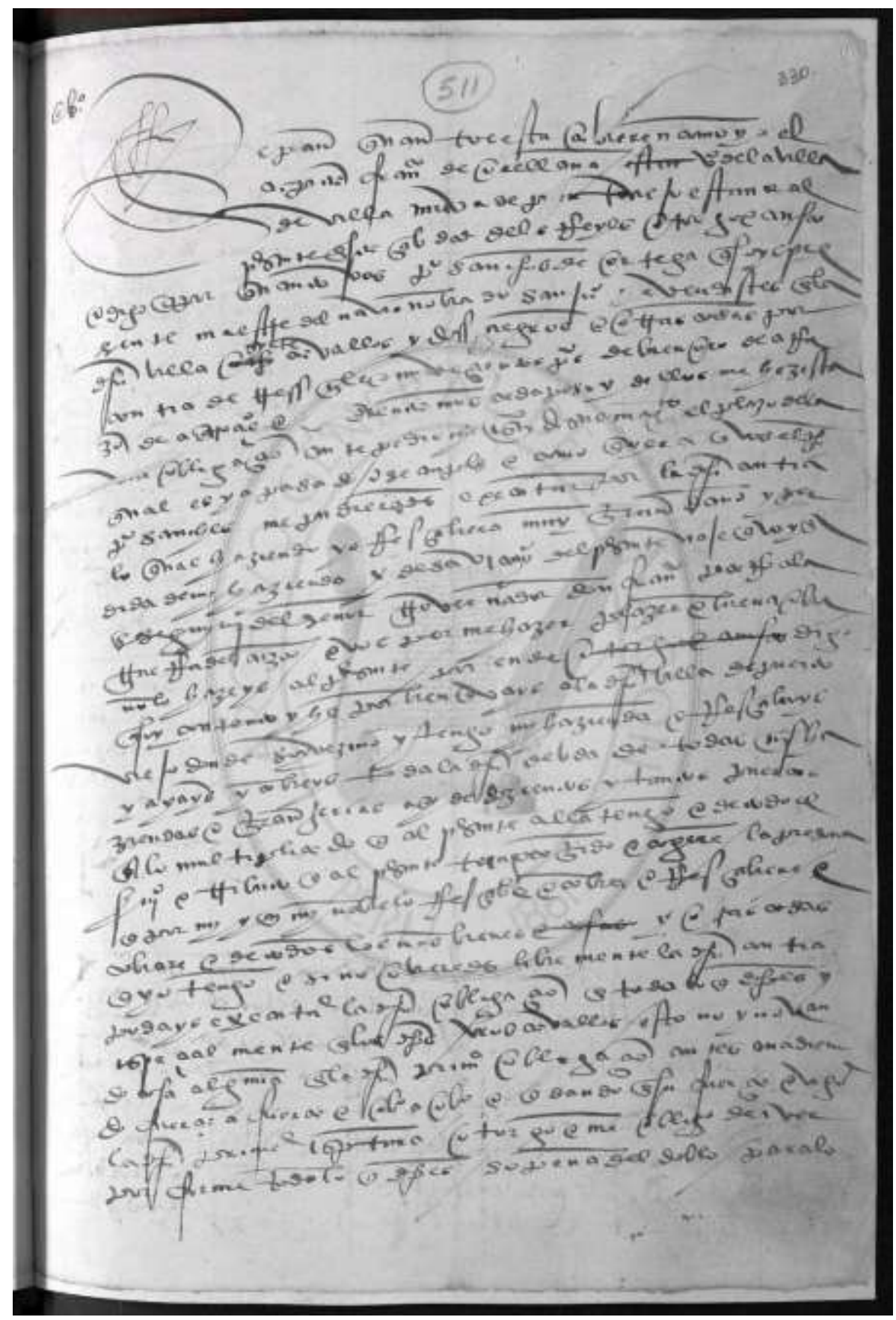

Fuente: Archivo General de la Nación del Perú, Signatura: N_1_PAC1_0,513_330-330v_0825, Folio 330 
DOCUMENTO 2.- CARTA DE OBLIGACION DE DEUdo POR MAYOR CUANTÍA, DEL CAPITÁN Francisco Pacheco vecino de Puerto Viejo a favor de un tal francisco Milanés, QUIEN LE PRESTA CIEN PESOS DE ORO; EN QUE SE ACLARA DEVOLVERLOS EN VEINTE DÍAS, A SU Regreso de la Provincia de NiCARAgua, SO PENA del doblo Al COBRo DE la CANTIDAd O DE LA COBRANZA DE SUS BIENES MUEBLES Y RAICES QUE POSEE EN LA VILLA DE PUERTO VIEJO (Lima, Gobernación de Nueva Castilla 06.12.1537).

${ }^{16}$ Fecha deudo.- Sepan quantos esta carta vieren como yo, Françisco Pacheco Veçino de Puerto Viejo estante al presente en esta Çiudad de los Reyes de la Nueva Castilla otorgo e conozco por esta presente carta que devo e me obligo a dar e pagar, a vos Françisco Mylanés que estays presente o a quyen vuestro poder oviere esta carta, por vos mostrare çien pesos de oro de valor, cada uno de quatroçientos e çinquenta maravedis, los quales son por razón y defecto de una obligaçion de mayor coantia que yo de vuestra a pro orejan ${ }^{17}$, e lo ovistes vos de aver por traspaso de que yo fuy contento e en ello resçibí buena obra, çerca de lo qual renunçio la exepçión de los dos años que ponen las leyes en derecho de la pecunya e de la cosa non vista ny contada, e todas las otras leyes que en my favor sean, los quales dichos çien pesos de oro deste dicho vuestro deudo prometo e me obligo de vos los dar e pagar dentro de veynte días después que llegare a la provynçia de Nycaragua, e sino fuere a la dicha provynçia dentro de seys meses conplydos prymeros syguyentes, a costos de oy día de la ffecha desta carta donde quyera que me los pidieredes e demandaredes syn pleito e syn contienda alguna, so pena del doblo e costas e la dicha pena pagada o no, que toda ya sea firme lo en esta carta contenydo, para lo qual conplir, doy e otorgo poder cumplydo a todos e qualesquier Alcaldes e Justiçias de Sus Magestades ${ }^{18}$ a la jurysdiçión de las quales me someto renunçiando my propio fuero para que por todo rigor de derecho me executen e puedan e vendan mys bienes en plata de moneda o fuera della, e de su valor entreguen e hagan pago a vos el susodicho deste dicho deudo prinçipal e costas de todo, byen e complydamente como sy lo que dicho es ansy fuese juzgado e sentençyado por juiçyo de Juez competente e la tal sentençya fuese por my consentida e pasada en cosa juzgada, çerca de lo qual renunçio todas e qualesquyer leyes e fueros e derechos que en my favor sean, e la ley e regla de derecho en que diz que general renunciaçion hecha de leyes non vala e para lo cunplyr e pagar e aver persona segund dicho es, obligo my persona e todos mys bienes muebles e rayzes avidos e por aver, fecha la carta en la dicha Çiudad de los Reyes seys días del mes de Diziembre año del Señor de myll e quynyentos e treynta e syete años, y el dicho otorgante lo firmó de su nonbre en el registro, testigos que fueron presentes a lo que dicho es Yñigo ${ }^{19}$ de Vitoria e Alonso de Navarrete e Juan Díaz de Melgar, estantes en la dicha Çiudad ${ }^{20}$. (f) Françisco Pacheco. Pasó ante my; Pedro de Castañeda. Escryvano Público.

\footnotetext{
${ }^{16}$ Archivo General de la Nación del Perú, Signatura: N_1_PCA1_18,227_314_0303, Inicio folio 314.

${ }^{17}$ Alocución latina que merece ser consultada dado su poco uso. Significa traducida literalmente al castellano: Provecho o uso de la escucha.

${ }^{18}$ Tachado: a la juridyçion para que.

${ }^{19}$ La abreviatura del nombre es literalmente "I $n$ ", pero la falta de la " $g$ " descarta la posibilidad de colocar en el descifrado el nombre "Ignacio". Además, el apellido "de Vitoria" nos hace recordar que se trata de alguien con ascendencia vasca.

${ }^{20}$ Va entre renglones o dize costos de oy dya de la fecha desta carta.
} 


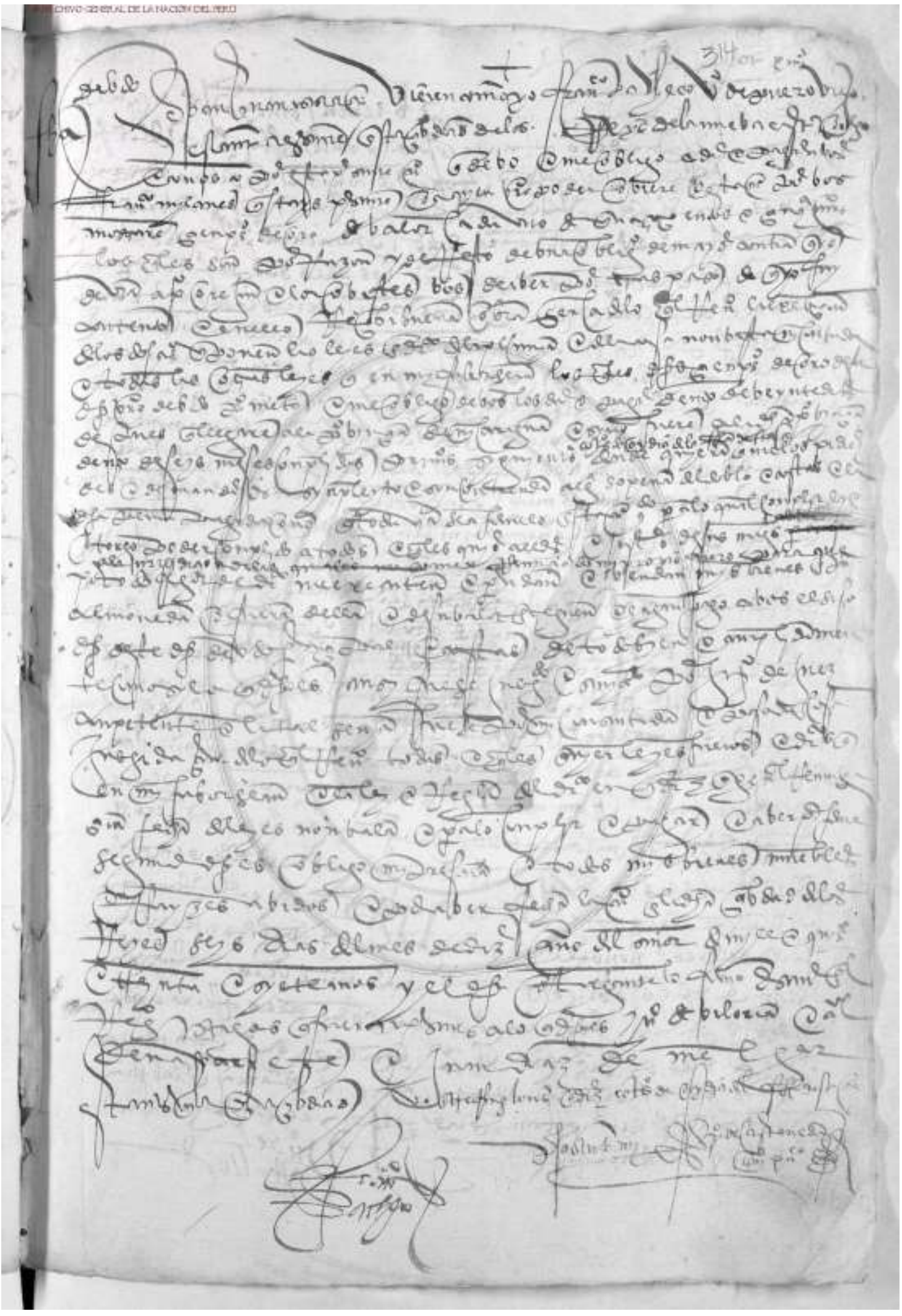

Fuente: Archivo General de la Nación del Perú, Signatura: N_1_PCA1_18,227_314_0303, Inicio folio 314. 
DOCUMENTO 3.- CARTA DE PAGO Y COMPRA DE DOS CABALlOS, BLANCO Y MORCILlO; Y UN

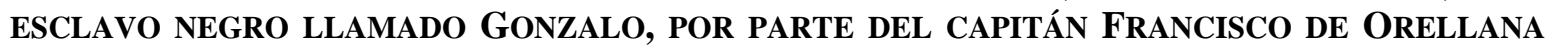
Vecino de Puerto Viejo a Hernando bachicao, por 2000 pesos de buen oro, para PAGARLOS EN UN TÉRMINO DE SEIS MESES DE FECHADA LA CARTA CON LA GARANTÍA DE SU HIPOTECA, Y PROHIBIENDOSE LA TOTAL O PARCIAL ENAJENACIÓN DE CUALQUIERA DE ELLOS (Lima, Gobernación de Nueva Castilla 08.06.1537).

${ }^{21}$ Sepan quantos esta carta vieren como yo el Capitán Françisco de Orellana Vezino de la Villa de Villa Nueva de Puerto Viejo otorgo e conosco por esta presente carta que devo e me obligo (de) dar e pagar a vos Hernando Bachicao que soys presente o a quyen vuestro poder oviere, conviene a saber dos myll pesos de buen oro fundido e marcado de valor cada un peso de a quatroçientos e çinquenta maravedís, los quales son por razón de dos cavallos, el uno todo blanco y el otro morzillo con una casta en la frente, e un negro que se dize Gonçalo que de vos compré e resçibí de los quales soy contento, y entregado a my voluntad y a vista de Albeytar ${ }^{22}$, y los resçibió porque son sanos, sobre lo qual renuncio las leyes del mal engaño e de la entrega e paga, como en ellas se contyene, los quales dichos dos myll pesos de oro, otorgo e me obligo de deverlos dar e pagar de oy día de la fecha desta carta en seys meses conplidos primeros syguyentes, e que sí antes de cumplido el plazo, yo pasare adelante del Cuzco que por el mesmo caso se cumpla el termyno desta obligaçión, so pena del doblo e costas o la pena pagada o no, que lo que dicho es firme sea e válida, para $10 /{ }^{23}$ qual, así tener e mantener e guardar e cumplir e pagar e aver por firme, obligo my persona o bienes rayzes e muebles avydos e por aver, e para la execuçion, seguridad e cumplimyento de la dicha paga, vos ypoteco los dichos cavallos e negro por espeçial ypoteca, para no lo poder vender, dar, donar, trocar, ny en manera alguna enajenar, so pena que si lo vendiere o enajenare que la tal venta o enajenamyento sea en sí ninguna e de nyngún valor y efeto, e para la seguridad e cumplimyento desta carta, e de lo en ella contenydo lo doy e otorgo en todo poder cumplido a qualesquyer justiçias e Juezes de Sus Magestades de qualquier fuero e jurisdicçión que sean que me constrengan ${ }^{24}$, conpelan e apremyen a lo asy complir e pagar, asy por vía del execuçion, prisión, trança e rescate, como en otra qualquyer manera buena, sí como si lo que dicho es fuese sityado por sentençya difinityva de Juez competente, por my consentida e pasada en cosa juzgada sobre lo qual renuncio todas e qualesquyer leyes, fueros e derechos que sean en my (favor), e partidas, casadenamyentos ${ }^{25}$, priçiones e defensiones que sean en my favor e espeçialmente renunçio la ley e derecho que dize que general renunçiaçión, fecha de leyes no val(id)a en testimonyo de la qual otorgué esta carta ante el Escryvano e testigos yusoescritos en el Registro de lo qual firmé my nonbre.

\footnotetext{
${ }^{21}$ Archivo General de la Nación del Perú, Signatura: N_1_PAC1_0,509_326v-327_0816, Vuelta folio 326.

${ }^{22}$ El Albeytar es el equivalente actual entre el veterinario rural y el médico de campo, pero especializado en animales de carga, transporte y defensa personal. En los siglos XVI Y XVII, estaba sobrevalorado este oficio, paralelamente conviviendo con la caballería o la montería, de importancia social debido al valor que se les daba a las razas por su crianza, reproducción, salud y manutención. Los animales de carga como el caballo hacían parte de los círculos de alto poder adquisitivo, y la manufactura y la agricultura necesitaban de la fuerza de estas bestias cuadrúpedas, derivadas como medio de producción de trabajo bruto y crecimiento económico. La mentalidad castellana de entonces, elogiaba muchísimo a las artes vinculadas a la equitación y al hecho de montar a caballo como símbolo de distinción y poder, así como por los altos costos que implicaban entonces su adquisición como lo relata el documento. Se trata del "Artífice" o del "Médico" que se dispone a curar las enfermedades, otorgar pronósticos, preparar medicamentos no solo de los animales de carga, sino también de quienes los usaban o montaban. El Albeytar también fue un médico no colegiado, empírico, solidario y buen samaritano que socorría a los enfermos y a los menesterosos en los trajines de camino. Su experticia experimental sobre la salud animal, no le condicionó a aplicar sus métodos en la salud humana, principalmente la de las personas que trabajaban viajando o trasladando cosas. M. Arredondo. Recopilación de Albeyteria, sacada de varios autores. Ed. por J. d. Valdés (Madrid, España, 1658).

${ }^{23}$ Archivo General de la Nación del Perú, Signatura: N_1_PAC1_0,509_326v-327_0817, Inicio folio 327.

${ }^{24}$ De constreñir.

${ }^{25}$ De casación.
} 
Ques fecha e otorgada en la Çiudad de los Reyes, ocho días del mes de Junyo año de myll e quinyentos e treynta e syete años, siendo testigos presentes Diego Fernández de Truxillo e Domyngo de la Presa e Joan de Mora Veçinos y estantes en esta Çiudad.

Ypoteca negro y (dos) cavallos. - (f) Françisco de Orellana. Ante my; (f) Antonyo de Olivares. Escryvano.

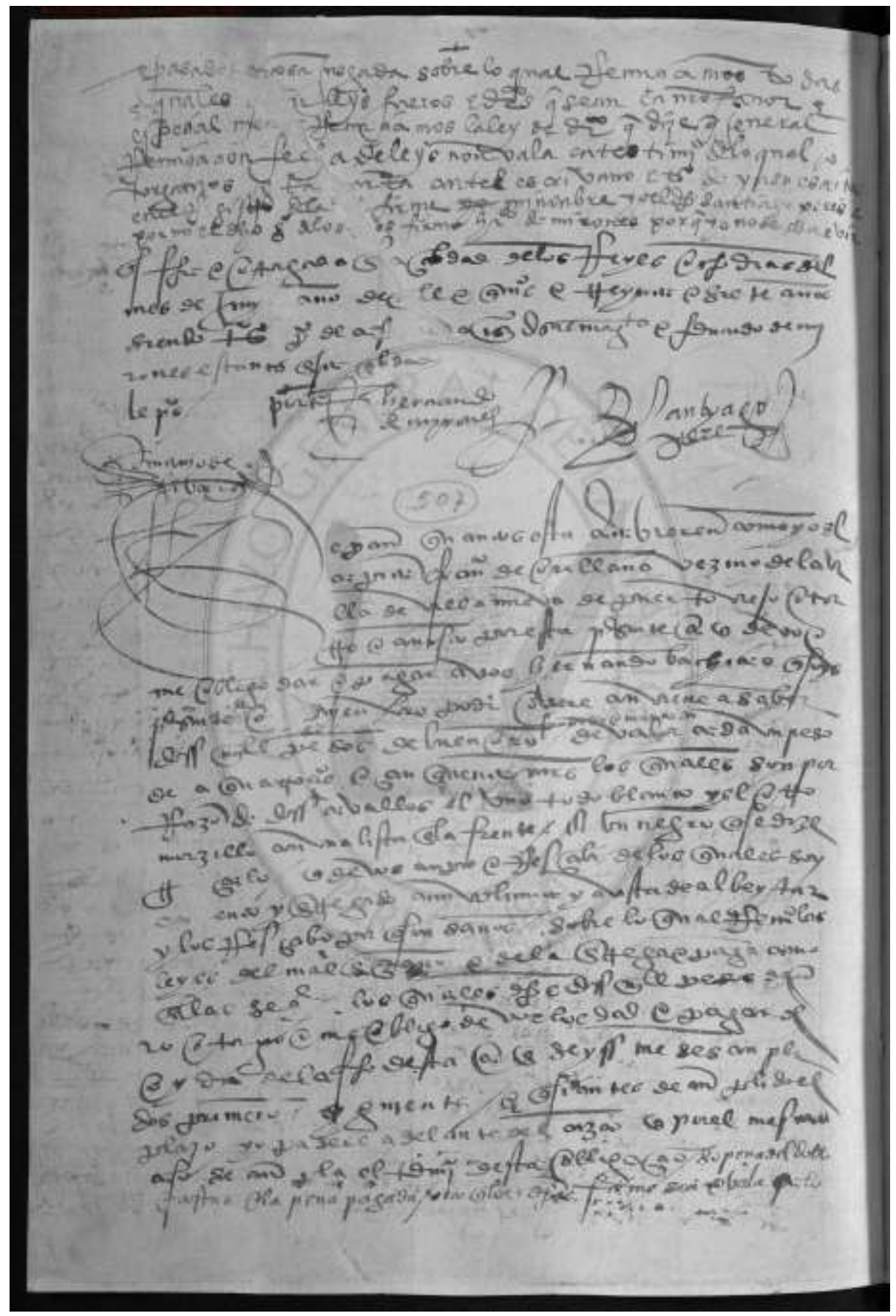

Fuente: Archivo General de la Nación del Perú, Signatura: N_1_PAC1_0,509_326v-327_0816, Vuelta folio 326. 


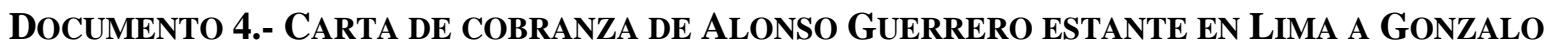
de Olmos teniente de la Provincia de Puerto Viejo y a Baltazar García vecino de PUERTO VIEJO, POR LA CANTIDAD DE 140 PESOS DE ORO, MEDIANTE TRANSMISION EN PODER DE reclamo a Alonso bolaños, Que Se encuentra en Puerto Viejo (Lima, Gobernación de Nueva Castilla 07.06.1538).

${ }^{26}$ Sepan quantos esta carta vieren como yo, Alonso Guerrero maestre estante que soy al presente en esta Çiudad de los Reyes de la Nueva Castilla Provinçia del Perú otorgo e conozco que doy e otorgo todo my poder cumplido libre, llenero e bastante, segund que lo yo he e tengo, e de derecho, más puede e deve valer a vos Alonso Bolaños estante en la Probynçia de Puerto Viejo, que estays ausente, bien ansí como sí fuesedes presente, espeçialmente para que por my y en my nombre, e como yo mismo, podays pedir e demandar, recaudar, resçebir, aver e cobrar, ansy en juyçio como fuera dél, de Gonçalo dOlmos Theniente de la dicha Probynçia, e de Baltasar Garçía, como mancomunados e de sus bienes, e de quyen e con derecho devays çiento e quarenta pesos de oro, quales sobre dichos, me deven por una obligaçión e para que de lo que reçibyeredes e cobraredes de lo que dicho es, o de qualquyer cosa o parte dello, podays dar e otorgar, e deys e otorgueys vuestra carta o cartas de pago e de finyquito, las quales valgan e sean firmes e valederas, como si yo mysmo las diese e otorgase e al otorgamyento dellas presente fuese.

E sy en razón de lo que dicho es, o de qualquyer cosa o parte dello, fuere nesçesario entrar en contienda de juyçio, podades paresçer e parescays ante todas e qualesquyer Justiçias, Alcaldes e Juezes de Sus Magestades de qualquyer fuero e juridiçión que sean, ansy eclesyasticos como seglares e antellos e qualquyer dellos podays hazer todos los pedimyentos e requerimyentos, entregas y execuçiones, presiones, ventas e remates de bienes e juramentos, en my anyma e de verdad decir, e todos los otros autos e diligençias judiçiales y estrajudiçiales, que al caso convengan e que yo mysmo haría e hazer podría presente syendo, e que segund derecho demande e requyera aver en sy, otro my mas especial poder e mandado e presençia personal, que para todo ello e lo dello dependiente, vos doy este dicho my poder conplido, e para que en vuestro lugar, y en my nonvre podays sostituyr un Procurador o más, e los revocar, cada que quysyeredes, quedando en vos este dicho poder prençipal e para lo aver todo por firme, obligo my persona $/{ }^{27}$ e bienes muebles e rayzes avydos e por aver, so la qual dicha obligaçión vos relievo a vos e a vuestros sostitutos segund forma de derecho, fecha la carta en la dicha Çiudad de los Reyes siete días del mes de Junyo año del nasçimyento de nuestro Salvador Iesu Xpo de myll e quynientos e treynta e ocho años y el dicho otorgante lo firmó de su nonbre en el registro, testigos que fueron presentes a lo que dicho es Pedro de Avendaño e Lorenço Roman e Diego de Medina estantes en la dicha Çiudad. (f) Alonso Guerrero.

\footnotetext{
${ }^{26}$ Archivo General de la Nación del Perú, Signatura: N_1_PCA1_18,646_732-732v_1070, Folio inicio 732.

${ }^{27}$ Archivo General de la Nación del Perú, Signatura: N_1_PCA1_18,646_732-732v_1071, Folio vuelta 732.
} 


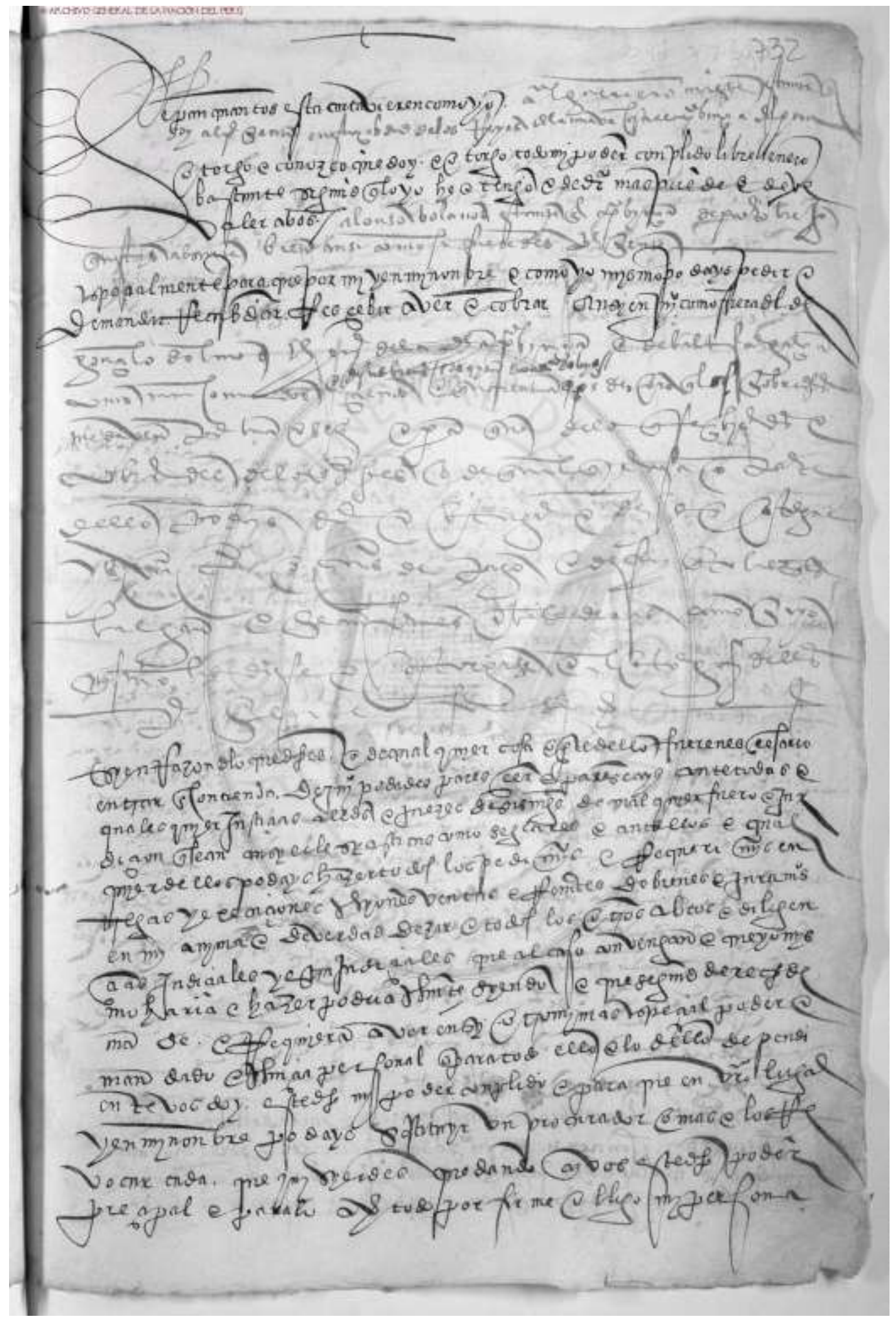

Fuente: Archivo General de la Nación del Perú, Signatura: N_1_PCA1_18,646_732-732v_1070, Folio inicio 732. 
DOCUMENTO 5.- CARTA de Obligación de JeRónimo de Aliaga Vecino de LiMA, PARA QUE Bartolomé Pérez Vecino de Puerto Viejo, pudiera allá cobrar de su derecho y NOMBRE PESOS DE ORO, MARAVEDÍS, DUCADOS, PLATA, JOYAS, CAVALLOS, GANADOS, ESCLAVOS NEGROS E INDIOS Y OTRAS COSAS QUE SE LE DEBAN AL ENTRETANTO (Lima, Gobernación de Nueva Castilla 16.07.1538).

${ }^{28}$ Fecha.- Sepan quantos esta carta vieren como yo, Gerónimo de Aliaga Veçino desta Çiudad de los Reyes de la Nueva Castilla Provynçia del Perú, otorgo e conozco que doy e otorgo, todo my poder complido, libre, llenero, bastante, segund que lo yo he e tengo e de derecho, más puede e debe valer a vos Bartolomé Pérez Vezino de la Villa de Puerto Viejo, estante en esta dicha Çiudad que estays ausente bien ansy como sy fuesedes presente, espeçialmente para que por my y en my nonbre, e como yo mysmo, podays pedir e demandar, recaudar, resçebir, aver e cobrar ansy en juyçio como fuera dél, de todas e qualesquyer personas, que sean destos bienes, e de quyen e con derecho devays todos los pesos de oro, maravedís e ducados, plata, joyas, cavallos, ganados, esclavos negros e yndios, e todas las otras cosas que me sean devydas, e me pertenezcan en qualquyer manera, ansy por obligaçiones como por sentençia definityva 3 ojas tres pesos, conpañyas y tierras corrientes como en otra qualquyer manera, e por qualquyer causa o razón que sea, e de lo que resçibieredes e cobraredes de lo que dicho es, o de qualquyer cosa o parte dello, podays dar e otorgar e deys e otorgueys una carta o cartas de pago e de Fynyquito, las quales valgan e sean firmes e valederas como sy yo, mysmo las diese e otorgase, e al otorgamyento dellas, presente fuese, e otrosy para que podays arrendar e arrendeys, el ofiçio de la sentençya mayor del Jusgado de la Provynçia de Puerto Viejo a la persona que os pareció e por el plaço o plaços, que bien visto os fueren, e lo que de quyen dicho es pudiere, me lo podays envyar e envieys a esta Çiudad de los Reyes, enpleado en piedras, esmeraldas, o en ganados o en dyneros, segund e de la manera que os paresçiere e qual navio e con la persona que os paresçiere e contyene, obligo o en manera que yo dare la presente pueda e me obligo de lo aver por firme.

E sy en razón, de lo que dicho es, o de qualquyer cosa o parte dello fuere nesçesario entrar en contienda de juyzio, podades paresçer e parescays ante todas e qualesquyer Justiçias, Alcaldes e Juezes de Sus Magestades, de qualquyer fuero e juridiçion que sean, ansy eclesyasticas como seglares e antellos o qualquyer dellos, podays hazer todos los pedimyentos e requerimientos, entregas y execuçiones, presiones, ventas e remates de bienes e juramentos, en my anyma e de verdad decir e todos los otros autos e diligençias judiçiales y estrajudiçiales que al caso convengan, e que yo mysmo haría e hazer podría presente, syendo e que segund derecho, demás dé e requyera aver en sy, otro my más espeçial poder, e mandado e presençia personal que para todo ello, e lo dello dependiente, vos doy este dicho my poder conplido, e para que en vuestro lugar y en my nonbre, podays sostituyr un Procurador o más, e los revocar cada que quysyeredes quedando en vos este dicho poder prençipal, e para lo aver todo por firme, obligo my persona e bienes muebles e rayzes avydos e por aver, so la qual dicha obligaçion vos relie ${ }^{29}$ vo a vos e a vuestros sostitutos, segund forma de derecho, fecha la carta en la dicha Çiudad de los Reyes, diez e seys días del mes de Jullyo, año del nasçimyento de nuestro salvador Iesu Xpo de myll e quynientos e treynta e ocho años, y el dicho otorgante lo firmó de su nonbre en el Registro, testigos que fueron presentes a lo que dicho es Gonçalo de Bolybar e Diego de Medina e Toribio platero, estantes en la dicha Çiudad. (f) Gerónimo de Alyaga.

\footnotetext{
${ }^{28}$ Archivo General de la Nación del Perú, Signatura: N_1_PCA1_18,661_742v-743_1101, Vuelta folio 742.

${ }^{29}$ Archivo General de la Nación del Perú, Signatura: N_1_PCA1_18,661_742v-743_1102, Inicio folio 743.
} 


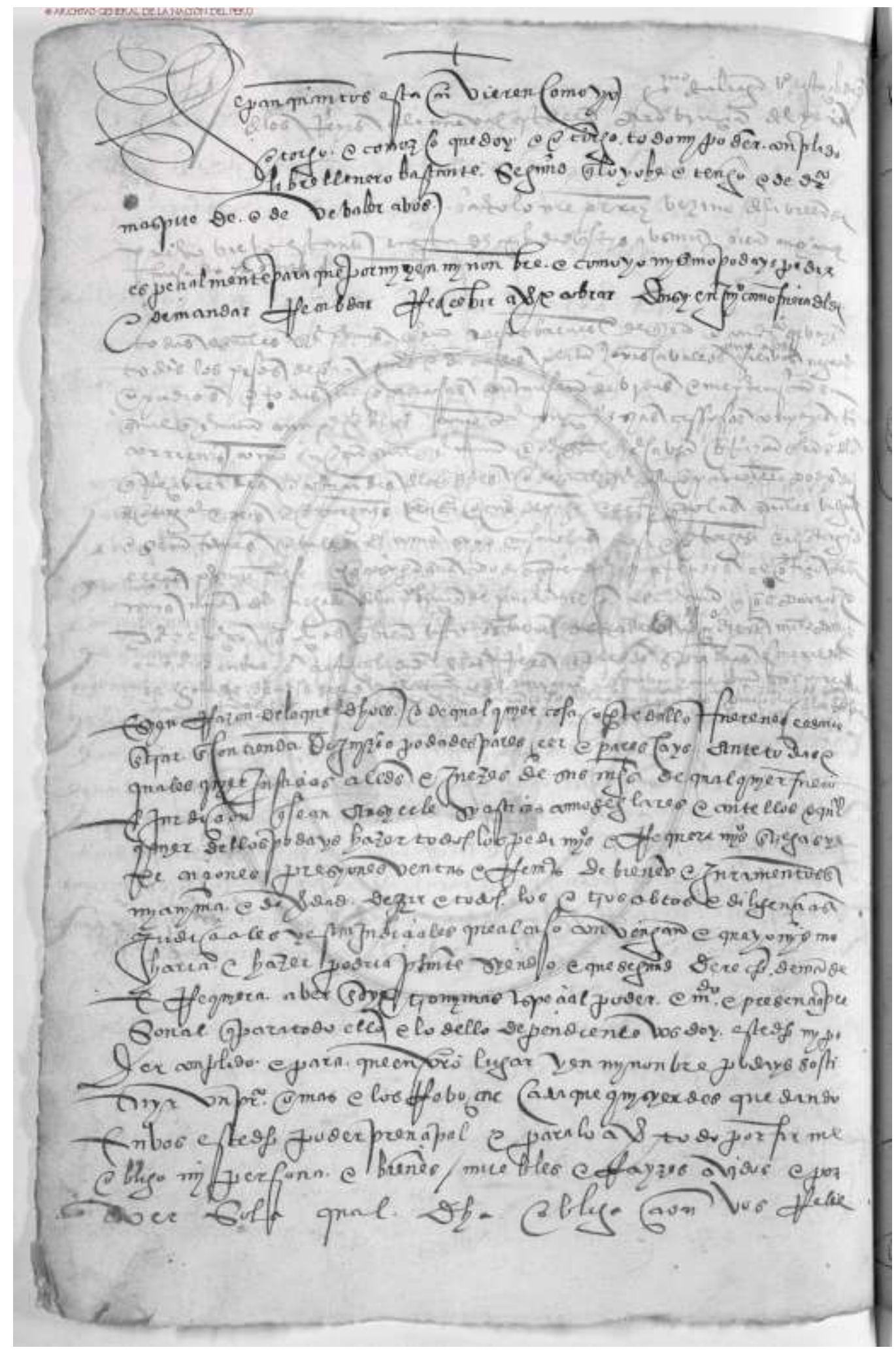

Fuente: Archivo General de la Nación del Perú, Signatura: N_1_PCA1_18,661_742v-743_1101, Vuelta folio 742. 
Documento 6.- CARTA de PODER DEl Teniente de gobernador de la CiUdAd de los Reyes francisco de Chaves, Para que Juan de Olmos, Bartolomé Pérez, ambos VECinOS DE PUERTO VIEJO; Y RODRIgo MARChENO TODOS AUSENTES, PUEDAN EN SU REPRESENTACIÓN COBRAR, RECIBIR Y OBLIGAR LAS DEUDAS EN DINEROS O BIENES MUEBLES Y RAICES QUe LE TIENEN PENDIENTES OTRAS PERSONAS EN LA Villa de PUERTO Viejo (Lima, Gobernación de Nueva Castilla 30.07.1538).

${ }^{\beta 0}$ Poder.- Sepan quantos esta carta vieren como yo, Françisco de Chaves Thynyente de Governador e Capitán en esta Ciudad de los Reyes de la Nueva Castilla por el Muy Magnifico Señor Don Françisco Piçarro, Adelantado Capitán General e Governador por Sus Magestades en estos Reynos de la dicha Nueva Castilla, otorgo e conozco que doy e otorgo todo my poder cumplido lybre, bastante e llenero, segund que lo yo he e tengo e de derecho, más puede e deve valer a vos Juan dOlmos e Bartolomé Pérez Veçinos de la Villa de Villanueva de Puerto Viejo, e a Rodrigo de Marcheno que estays ausentes, como sy fuesedes presentes, a ambos, a dos juntamente y a cada uno e qualquyer de vos por sy yn solidum, espeçialmente para que por my, y en my nonbre y como yo mysmo, podays demandar, recaudar, resçibyr, aver e cobrar, ansy en juyzio, como fuera dél deudas e causas a personas que sean e de su nonbre y de quyen con derecho devays todo oro, plata, joyas, perlas, maravedís, esclavos, cavallos, negros, yndios e otras qualesquyer cosas que ansy tocan de traer e me presentar por obligaçiones, conosçimyentos, sentençyas, trespasos, como en otra qualesquiera manera, casso o razón que sea e de lo que rescybieredes e cobraredes, deys e otorgueys unas cartas de pago e finequyto e vala, e sean tan reales e valederas, como sy yo mysmo vendiese e otorgase, e a la data presente fuese, e para que lo en que proçediere de las dichas mys deudas, me lo podays envyar e envieys a my con sygnado, a esta dicha Çiudad a my riesgo e ventura, asy en razón de la dicha cobrança fuere nesçesario entrar en contienda de juyzio, podays pasar e paseys a mí, e qualesquier Alcaldes, Justiçias e Juezes de Sus Magestades, de qualquyer fuero e jurisdiçión que sean, e haçer todas las execuçiones, presyones, ventas e remates de byenes, e juramentos en my anyma e de verdades, e todos los otros autos e deligençias judiçiales y estrajudiçiales, que al caso convenga e que yo mysmo haría presente seyendo, e porque en vuestro lugar y en my nonbre podays sostituyr un Procurador e los renovar, que para todo ello e lo a ello anexo e dependiente, vos doy este dicho my poder conplydo, e para lo aver todo por forma, obligo la dicha my persona e bienes muebles e rayzes avidos e por aver, so la qual dicha obligaçión sy nesçesario es, vos relievo según forma de derecho, ffecha la carta en la dicha Ciudad de los Reyes, treynta días del mes de Jullio, año del nasçimyento de nuestro Salvador Iesu Xpo de myll e quynientos e treynta e ocho años, y el dicho Señor Françisco de Chaves, lo firmó de su nonbre en el Registro, testigos que fueron presentes a lo que dicho es, Joan de Barrios e Xpoval de Vargas e Joan Pérez Veçinos de la dicha Çiudad. (f) Françisco de Chaves.

${ }^{30}$ Archivo General de la Nación del Perú, Signatura: N_1_PCA1_18,559_662_0894, Inicio folio 662. 


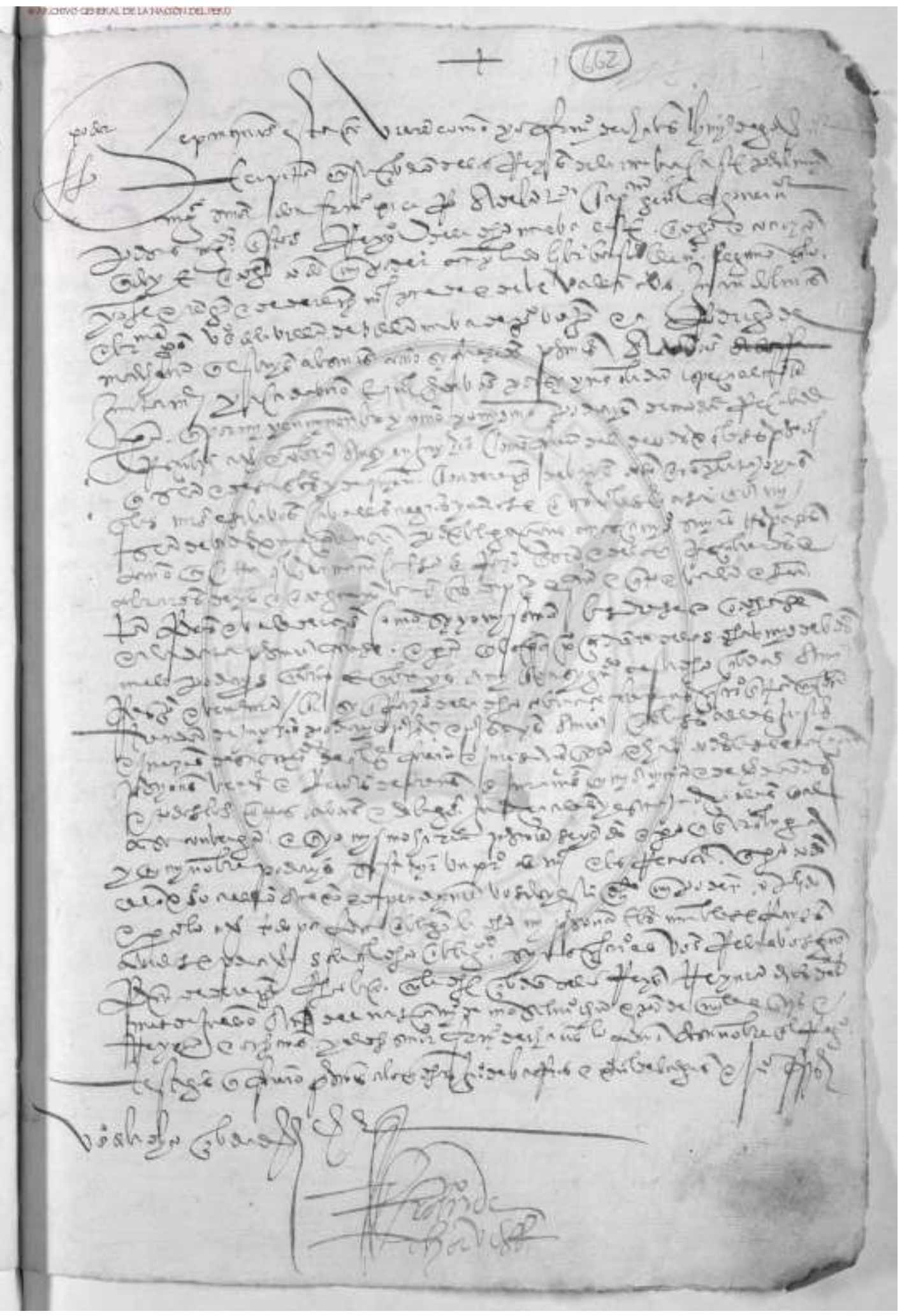

Fuente: Archivo General de la Nación del Perú, Signatura: N_1_PCA1_18,559_662_0894, Inicio folio 662. 


\section{Documento 7.- Carta de Pago de Cristóbal de Ayala vecino de Puerto Viejo a Juan DEL VALLE VECINO DE CUZCO POR LA COMPRA DE UN CABALLO DE COLOR CASTAÑO ENSILLADO Y ENTRENADO POR ÉL MISMO (Cuzco, Gobernación de Nueva Castilla 05.06.1535).}

${ }^{\beta 1}$ Fecha.- Sepan quantos esta carta vieren como yo, Xpoval de Ayala Veçino de Puerto Viejo, otorgo e conozco por esta presente carta que me oblygo de dar e pagar a vos Joan del Valle, o a quien por vos los oviere de aver es a saber, myll e quynientos pesos de buen oro fundido, marcado de valer cada peso de quynyentos e çinquenta maravedís, los quales sean por razón de un cavallo de color castaño ensillado y entrenado que de vos resçibe a comprado, del qual dy por entregado dél, porque todo lo resçibí e pasó asy todo de Real Otorgamyento, de lo qual renunçio la exebçión del mal engaño e de la y(nu)merata pecunya de lo aver no visto cuidado ny contado ny resçibido, y es el plazo a que oblygo de vos los dar e pagar los dichos myll e quynientos pesos de oy día de la ffecha desta carta en diez meses próximos syguyentes, y llanamentos syn pleito e syn contienda alguna, so pena del doblo, e la dicha pena pagada o non, que todavya vos dé e pague este dicho debido por cumplir e demás desto, sy lo ansy no tuvieredes e guardare; e conplydo segund como dichas por esta carta, e con ella ruego e pido, e doy e otorgo todo my poder conplydo, a todos e qualesquier Alcaldes e Juezes e Justiçyas de Sus Magestades a la yntençión de los quales e de cada uno dellos, me someto con la dicha my persona e bienes para qual ansy soy, otorgando personajes sobre esta dicha razón, llamado ante juyçyo requerido, oydo ny vençido sobre esta dicha razón me puedan presentar e presentare, e hagan e manden haçer otorgar, y execuçión en la dicha my persona e bienes lo qual que a my e a ellos hallaren, e los yo arya e los vendan e remitan en pública almoneda o fuera della a buen recato ${ }^{32}$ o a malos ynatendimyentos, guardar plazo ny haçer en alguna querella dello con juzgamyento, los suyos que volvyeren vos entreguen, e hagan luego pago deste dicho debido prinçipal, e de la pena del doblo sy en ella cayere, e de las costas quales vos revendiere de todo bien e conplydamente en guysa que vos no mengüe ny falte ende cosa alguna por pagar bien asy e a tan cunplydamente, como sy lo que dichas fuese cosa juzgada e pasada en pleyto por demanda e por respuesta, e fuese dada sentençya definityva por Juez competente e fuese por my consentyda e pasada en cosa juzgada, sobre la qual renunçio e parto, e quiero de my e de my favor e ayuda e defensyon, todas e qualesquier leyes, fueros e derechos de que en este caso me puedan ayudar e aprovechar en el provecho los derechos en que dize que general renunçiacion fecha de leyes non vala, e para lo asy conplyr e pagar, obligo my persona e todos mys bienes muebles e rayzes semovyentes avidos e por aver, fecha la carta en esta dicha Çiudad del Cusco, a çinco días del mes de Junyo año del nasçimyento de nuestro Salvador Iesu Xpo de myll e qunynyentos e treynta e çinco años, testigos que fueron presentes a lo que dicho es Joan Flores e Françisco Telles, estantes en esta dicha Çiudad e el dicho Xpoval de Ayala lo firmó de su nonbre. (f) Xpoval de Ayala.

\footnotetext{
${ }^{31}$ Archivo General de la Nación del Perú, Signatura: N_1_PAC1_0,776_521v_1286, Inicio folio 770.

${ }^{32}$ Recaudo.
} 


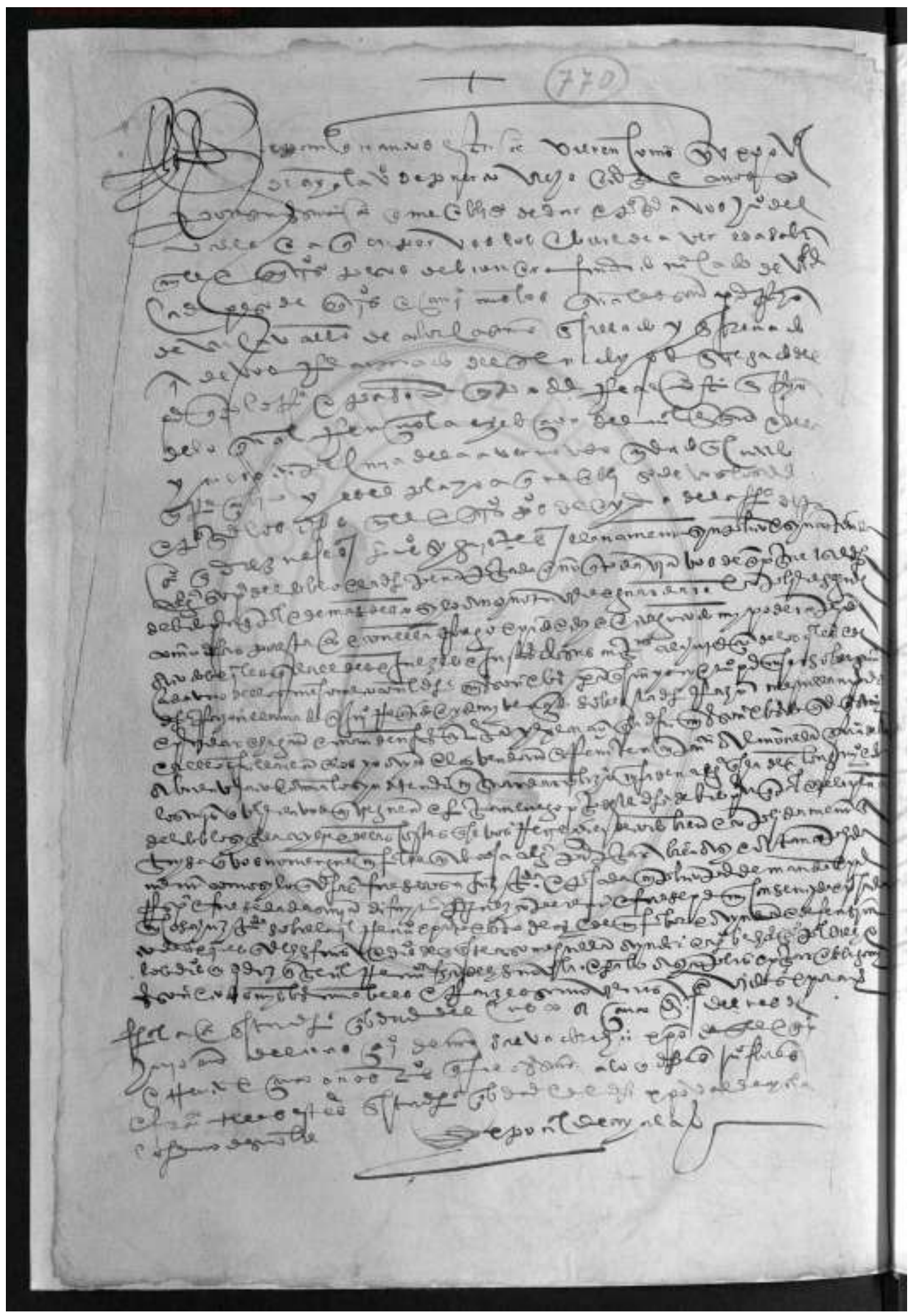

Fuente: Archivo General de la Nación del Perú, Signatura: N_1_PAC1_0,776_521v_1286, Inicio folio 770. 
Documento 8.- Carta incompleta de deudo, de JuAn de Jaen Vecino de Puerto Viejo A AlONSO VASQUEZ Y SU HERMANO POR LA CANTIDAD DE CINCUENTA Y CINCO PESOS DE ORO DE CIERTOS FLETES QUE SE LE HICIERON POR UN TAL DE ORTEGA, UNA VEZ PASADOS LOS DOS MESES DE HECHA LA CARTA (Lima, Gobernación de Nueva Castilla 31.05.1538).

${ }^{\beta 3}$ Deudo fecha. - Sepan quantos esta carta vieren como yo, Joan de Jaen Veçino de la Villa de Villa Nueva de Puerto Viejo estante que soy al presente en esta Çiudad de los Reyes de la Nueva Castilla provynçia del Perú otorgo e conozco por esta presente carta que devo, e me obligo a dar e pagar a vos Alonso de la ...... e a vos ....... Vásquez su hermano e a qualquyer de vos e al que tiempo .... de vos ..... qualquyer de vos oviere, e por vos o qualquyer de ..... lo oviere ...... e de recaudar çinquenta e çinco pesos de oro de valor cada uno ...... tresçientos e çinquenta maravedís, los quales son por razón echos ...s...qual... entregar de llano en llano, haçiendo de deuda a ..... (Juan Sánchez) de Ortega $^{34}$ de çiertos fletes echos de vuestra .................... otorgar poder segund dicho es, e renunçio que no .......... lo que dicho es no fue ny pasó ansy, e si lo di......... non vala sobre lo qual renunçio la exebçión de ........... es en derecho de la pesya e de la cosa non vista......... e la ley e exebçión del engaño segund .......los quales dicho es çinquenta e çinco pesos de ${ }^{35}$ oro, deste dicho deudo prometo e me obligo de vos los dar e pagar a donde quyera que me los pydieredes e demandaredes de oy .......... fecha desta carta en dos meses conplydos prymeros siguientes....... e syn contienda alguna so pena del doblo e costa ........ la pena pasada o no, que lo que dicho es valga e sea firme para lo ........ dar e pagar, obligo la dicha my persona e bienes muebles e rayces avydos e por aver, e doy e otorgo poder conplydo a todos (y a cada uno, ambos ante) qualesquyer Alcaldes e Juezes e Justiçias de Sus Magestades de qualquyera (partes e jurisdicción) que sean para que por todo rigor de derecho me lo hagan conplidamente ...... haga, y execuçion e persyvan em my, e en mys bienes, e los vendan e re(mitan en) publica almoneda o fuera della, e de su valor entreguen e hagan pago a ................. a qualquyer de vos deste dicho deudo pagarme, e costas e damos ynt(endimient)os cabos que de vos recreçieren de todo bien e conplydamente ............... dicho es, como sy fuese jusgado e syntinçiado por Juyzio de Juez (competente) ............... tal sentençya fuese por my consentida e pasada en cosa jusgada ............ renunçio todas e qualesquyer leyes, fueros e derechos que en my favor hagan para yr o venyr, como a lo que dicho es, que me nonvraran espeçial y esforsa(dame)nte renunçio la ley e rigor de derecho, en que dize que general renunçiaçion fecha de leyes non vala; fecha la carta en la dicha Çiudad de los Reyes treynta e un días del mes de Mayo, año del Señor de myl e quynientos e treynta e ocho años, y el otorgante lo fermó de su nonbre en el registro, seyendo presentes por testigos a lo que dicho es o........te Escryvano de Su Magestad e Lorenço Roman maestre e ............. Roman estantes en esta dicha Çiudad. (f) Joan de Jaen.

\footnotetext{
${ }^{33}$ Archivo General de la Nación del Perú, Signatura: N_1_PCA1_18,447_579-579v_0705, Inicio folio 579.

${ }^{34}$ De seguro el renglón de este folio carcomido, se refiere a Pedro Sánchez de Ortega, quien fuera maestre del navío nombrado San Juan, como lo especifica la escritura celebrada en Lima el 08.06.1537 en el documento 1, que trata un tema similar de fletes navieros o viajes por mar, y cuentas por cobrar. Se trata de un tipo de embarcación que por su tamaño no era muy común que surcara en demasía por los puertos y costas ecuatorianos y peruanos a la fecha de suscrita la escritura.

${ }^{35}$ Archivo General de la Nación del Perú, Signatura: N_1_PCA1_18,447_579-579v_0706, Vuelta folio 5.
} 


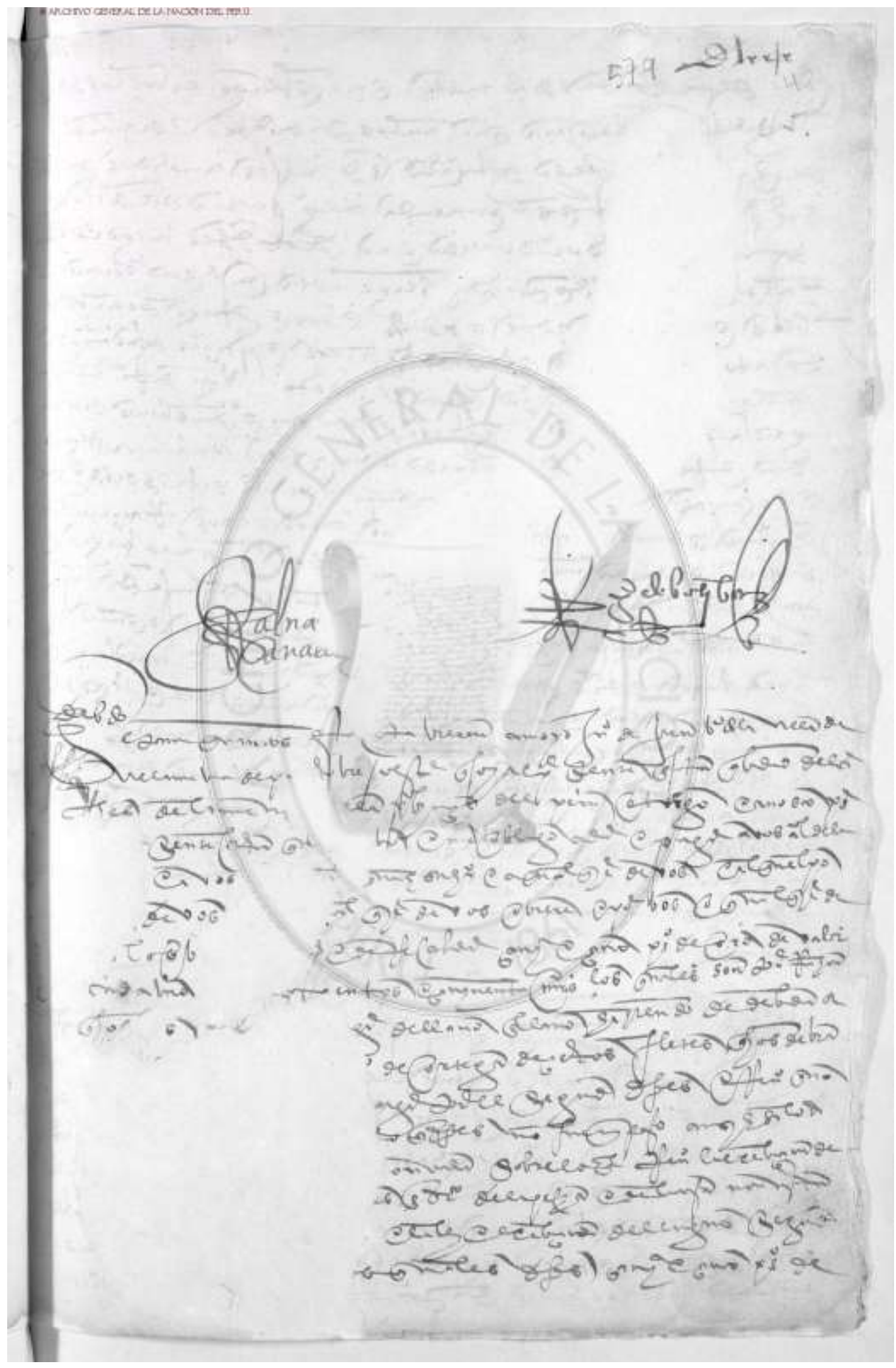

Fuente: Archivo General de la Nación del Perú, Signatura: N_1_PCA1_18,447_579-579v_0705, Inicio folio 579. 
DOCUMENTO 9.- CARTA DE CONCIERTO, PARA QUE ANDRÉS INDio NATURAL DE PUeRTo Viejo, PUEDA SERVIR POR TIEMPO DE UN AÑO A ALONSO RODRÍGUEZ DE OJEDA, POR LO CUAL RECIBIRÁ de PAGO EL INDIO 40 PESOS CORRIENTES DE A OCHO REALES, ASí COMO DEBERÁ VESTIRLE Y CURARLE SUS ENFERMEDADES EN DICHO TIEMPO (Puerto del Callao, Virreinato del Perú 26.11.1599).

${ }^{\beta 6}$ En el Puerto del Callao de la Çiudad de los Reyes, a veinte y seis días del mes de Noviembre de (mil quinientos) noventa e nueve años ante my; el Escribano e testigos pareçieron presentes Alonso Rodríguez de Ojeda y Andrés yndio natural de Puerto Viejo, ladino en la lengua española, y dixeron quellos son convenidos y conçertados en esta manera, el qual dicho yndio se obliga a sservir al dicho Alonso Rodríguez por tiempo de un año, cumplido primero siguiente, que corre y se quenta desde oy dicho día, por lo qual le a de dar e pagar al dicho yndio por el dicho tiempo, quarenta pesos corrientes de a ocho rreales el pesso, de vestir y curarle en sus enfermedades, y con esto se obliga de no se yr ni aussentar de Escrivano e de dicho Alonso Rodríguez, sepa de que si lo hiziere le apremien dello por todo rrigor de derecho, y el dicho Alonso Rodríguez se obligó de le pagar los dichos pesos al dicho yndio, pagades por sus terçios, y por el cumplimyento de lo que dicho es, obliguen sus personas y bienes avidos e por aver, e dieron poder a las justiçias de Su Magestad de qualesquier partes que ssean para que a ello les compelan e apremien, como por sentençia difinitiva, de Jues competente sobre que rrenunciaron todas las leyes de su favor e la general y derechos della, y dellos o dos otorgantes que yo el presente Escrivano doy ffee que conozco, lo ffirmó el presente Alonso Rodríguez y por el dicho yndio un testigo, siendo testigos Plaçido de Salinas y Juan de Uchuica presentes. A rruego y por testigos. (f) Alonso Rodríguez de Ogeda. (f) Placido de Salinas. Ante my; (f) Julián Bravo. Escrivano Público.

${ }^{36}$ Archivo General de la Nación del Perú, Signatura: N_1_JBR1_17,429_472v_0938. 


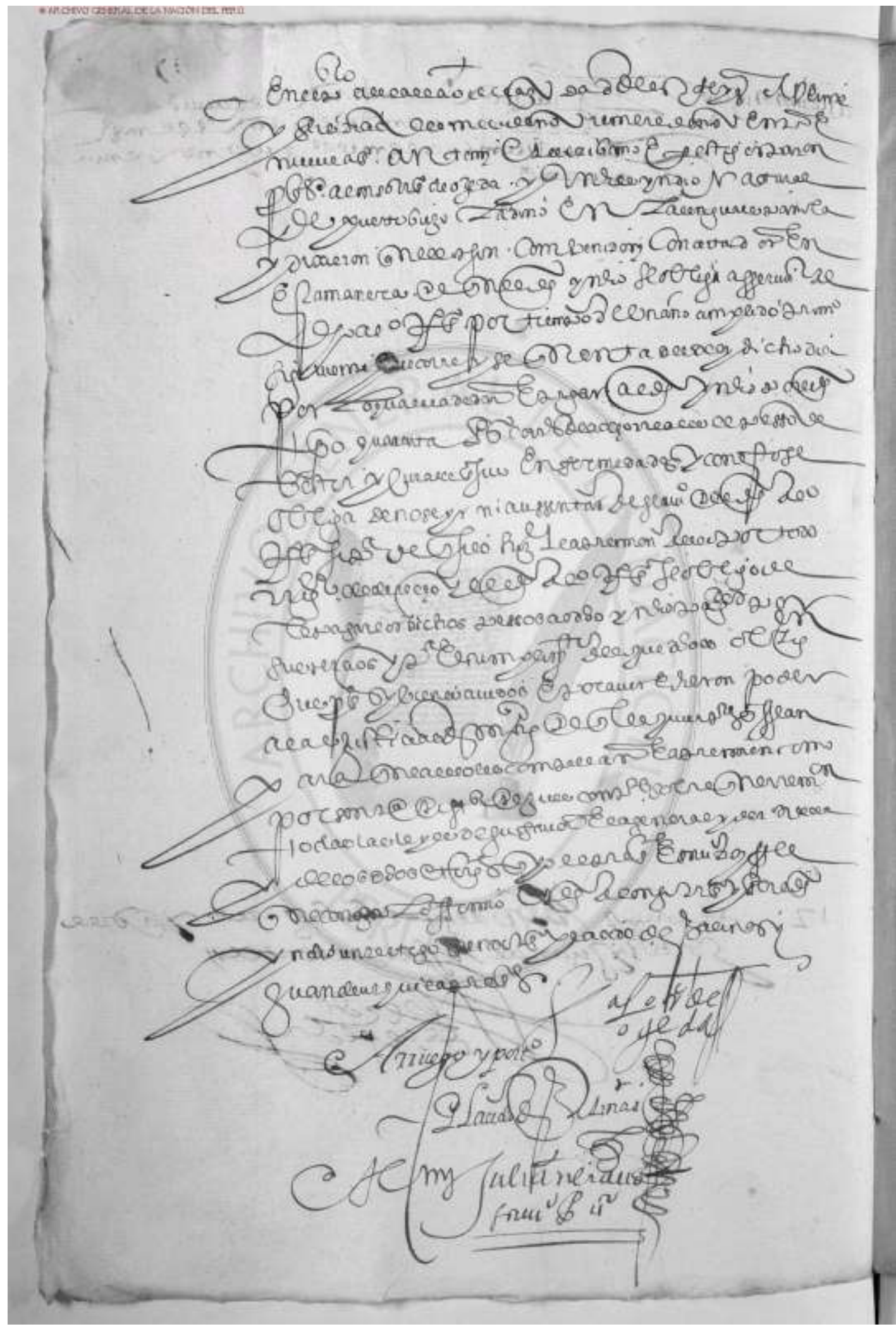

Fuente: Archivo General de la Nación del Perú, Signatura: N_1_JBR1_17,429_472v_0938. 
Documento 10.- Carta de Concierto Para Que Pedro Indio natural de Puerto Viejo, DE LA ENCOMIENDA DE NiCOlaS DE RIBERA, QUEDE ASENTADO A DIEgo DE PORRAS PARA QUE LE LABRARA UNA CHACRA POR TIEMPO DE UN AÑO, RECIBIENDO LA PAGA DE 20 PESOS CORRIENTES, TRES VESTIDOS DE ALGODÓN Y LAS TRES COMIDAS DEL DÍA, ASÍ COMO CURARLE EN SUS ENFERMEDADES (Lima, virreinato del Perú 05.10.1577).

$\beta^{37}$ En la Çiudad de los Rreyes en çinco días del mes de Otubre de mill e quynyentos y setenta y siete años el Señor Juan de Cadahalso Salazar, Visitador General en esta dicha Çiudad asentó a Pedro Yndio natural de Puerto Viejo de la Encomyenda de Niculas de Rribera, con Diego de Porras para ser labrador, en una chácara suya por tiempo de un año, que corre desde oy día de la fecha desta carta, por el qual le a de dar veinte pesos corrientes y tres vestidos de algodón y de comer, y si cayere enfermo curarle a su costa y hacerle enseñar las oraçiones y la doctrina xpiana, y que se confiesse a sus tiempos; y el dicho Diego de Porras que estava presente açeptó en el dicho syrviçio al dicho Pedro, para el dicho efecto, y se obligó de le dar los dichos veinte pesos y tres vestidos enteros, y hazer con él todo lo demás que está rreferido, y para lo ansy cumplir y pagar, obligo su persona y bienes avidos y por aver e dio poder bastante a las Justiçias de Su Magestad para que le compelan e apremien al cumplimyento y paga de lo que está rreferido en testimonyo, de lo qual (dio) e otorgó la presente, syendo testigos Françisco de Torres y Andrés Gonçales y Martín de Frías, y el dicho otorgante a quyen yo el Escrivano, conozco por quien no supo escrivir, rrogó a un testigo lo fyrmase por él y lo mesmo el dicho Señor Joan de Cadahalso. (f) Françisco de Torres. Ante my; Diego de Andrada. Escrivano de Su Magestad.

${ }^{37}$ Archivo General de la Nación del Perú, Signatura: N_1_AYO1_8,217_56_482. 


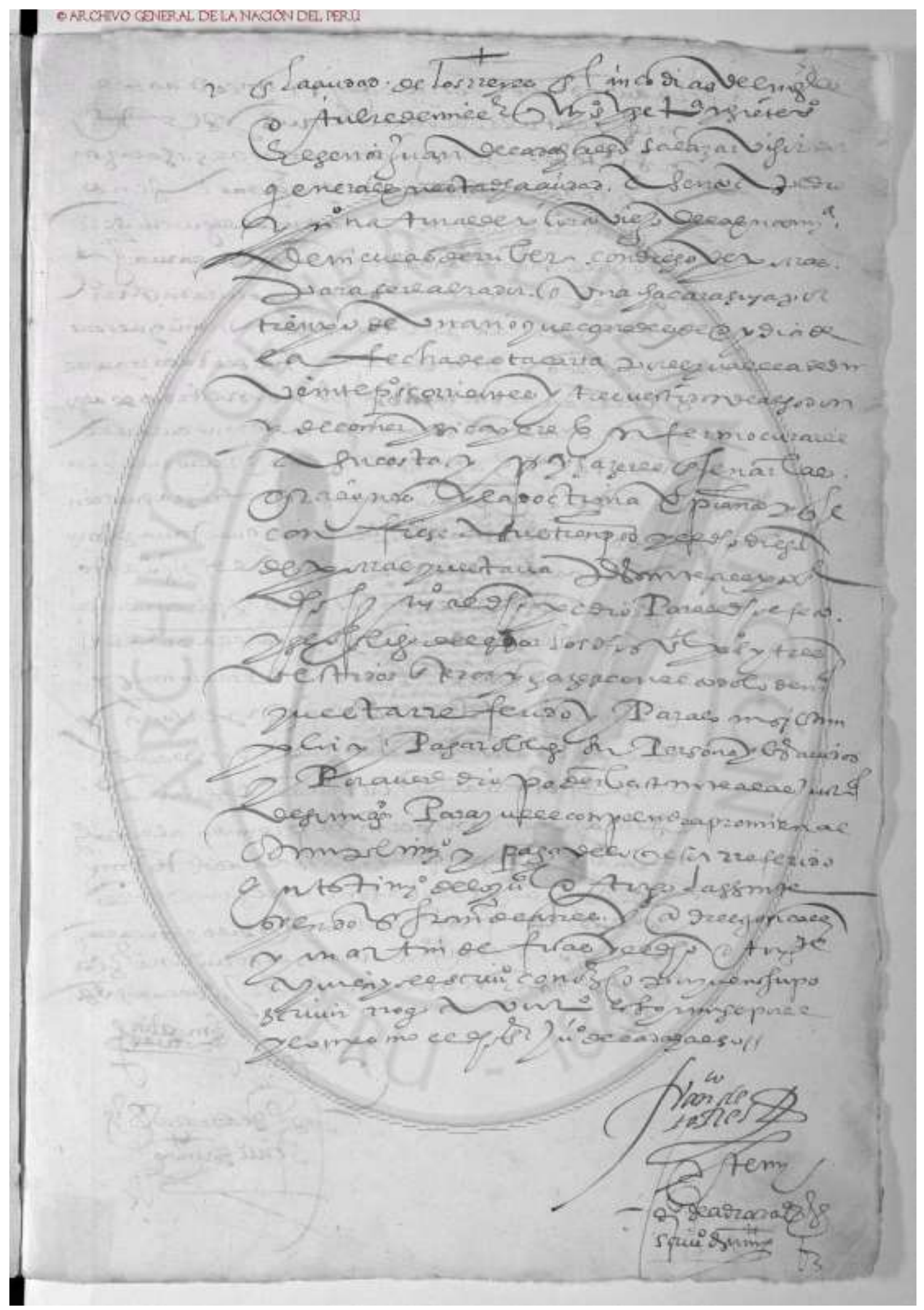

Fuente: Archivo General de la Nación del Perú, Signatura: N_1_AYO1_8,217_56_482. 
DOCUMENTO 11.- CARTA DE CONCIERTO PARA QUE EL INDIO LORENZO CHERRE NATURAL DE Puerto Viejo, pueda Servir a ANTONio Carrasco del SAZ Vecino de Lima, en todo lo QUE SE LE MANDE POR TIEMPO DE UN AÑO, CON LO CUAL SE LE HA DE PAGAR 24 PESOS DE A NUEVE REALES, DOS VESTIDOS DE INDIO, CURAR SUS ENFERMEDADES Y DOLENCIAS, DAR DE COMER Y BEBER, ASÍ COMO APRENDER LA DOCTRINA E IR A MISA (Lima, Virreinato del Perú 07.07.1599).

${ }^{\beta 8}$ Carta de Yndio.- En la Çiudad de los Reyes del Pirú a siete días del mes de Julyo de myll e quynyentos y noventa y nueve años, ante my el Escryvano de yuso escritos Don Juan de Sasaga Corregidor de los Naturales en la dicha Çiudad por Su Magestad, sentó a syrviçio a Lorenzo Cherre yndio que dijo ser natural de Puerto Viejo, con Antonyo Carrasco del Saz morador en la dicha Çiudad que estava presente, con quyen el dicho yndio quiso estar de su voluntad, para le servir en lo que le mandare que sea en esto por tiempo de un año cumplidos primero siguiente, que corre desde fecha desta carta deste dicho año, por razón que le a de dar veynte e quatro pesos de a nueve reales el peso, y dos vestidos de yndio, ordinarios de algodón que sean nuevos pagado ${ }^{39}$ en dos pagado $(s)^{40}$ en el dicho año en esta manera, en fin de cada seys meses, la mitad de la dicha coantía y un vestido y de comer el dicho tiempo y enviarlo a mysa y a la dotrina a las fiestas; y el dicho Corregidor, obligó a el dicho yndio, a que cumpla el dicho serviçio, y le mandó no haga falta ny ausençia con apercivimyento que sea apremyado a lo cumplyr por todo rigor de derecho, y el dicho Antonyo Carrasco del Saz otorgó que reçybe en su serviçio a el dicho Lorenzo Cherre yndio por el dicho tiempo de un año, desde el dicho día diez del mes de junyo próximo pasado, del año de la fecha desta carta, y se obligó de le dar y pagar los dichos veynte quatro pesos de la dicha plata corryente de a nueve reales el peso, y dos vestidos de yndio nuevos, a los dichos plazos en esta veçindad llanamente y syn pleyto alguno, con las costas de su cobranza y cumplyr, a todo lo demás contenydo en esta escryptura, segund y como en ella se declara, y no despedirá a el dicho yndio hasta ser cumplydo el dicho tiempo, e le pagará por entero, como sí le oviese servido, y a la firmeza de lo quiso dicho, obligo su persona e bienes avidos e por aver, y dio poder cumplydo a las justiçias de Su Magestad de qualesquyera partes que sean, para que por todo rigor de derecho le compelan e apremyen a la paga, execuçion y cumplymyento de lo contenydo en esta escritura, como si fuese por sentençia de Juez conpetente, pasada en cosa juzgada, y no apelada, y renunçio ${ }^{41}$ las leyes de su favor y defensas para la Ley Real del derecho, que defiende que general renunçiaçion fecha de leyes non vala, y lo otorgó así, siendo presentes con el dicho otorgante por testigo Pedro de Palma y Françisco Luyz Escryvano Real e resydientes en esta Çiudad, y ffírmolo el otorgante y el dicho Corregidor que yo el Escryvano conozco - va enmendado so dizel junyolentre rrenglones deste dicho año. (f) Don Juan de Sasaga. (f) Antonyo Carrasco del Saz. Ante my; (f) Rodrigo Alonso de Castillejo. Escryvano del Rey nuestro Señor. Derechos 4 reales.

\footnotetext{
${ }^{38}$ Archivo General de la Nación del Perú, Signatura: N_1_RAC1_22,185_239-240_0610.

${ }^{39}$ Archivo General de la Nación del Perú, Signatura: N_1_RAC1_22,185_239-240_0611.

${ }^{40}$ Pagado en dos pagados $=$ Pagado en dos pagos o fraccionados en dos.

${ }^{41}$ Archivo General de la Nación del Perú, Signatura: N_1_RAC1_22,185_239-240_0612.
} 


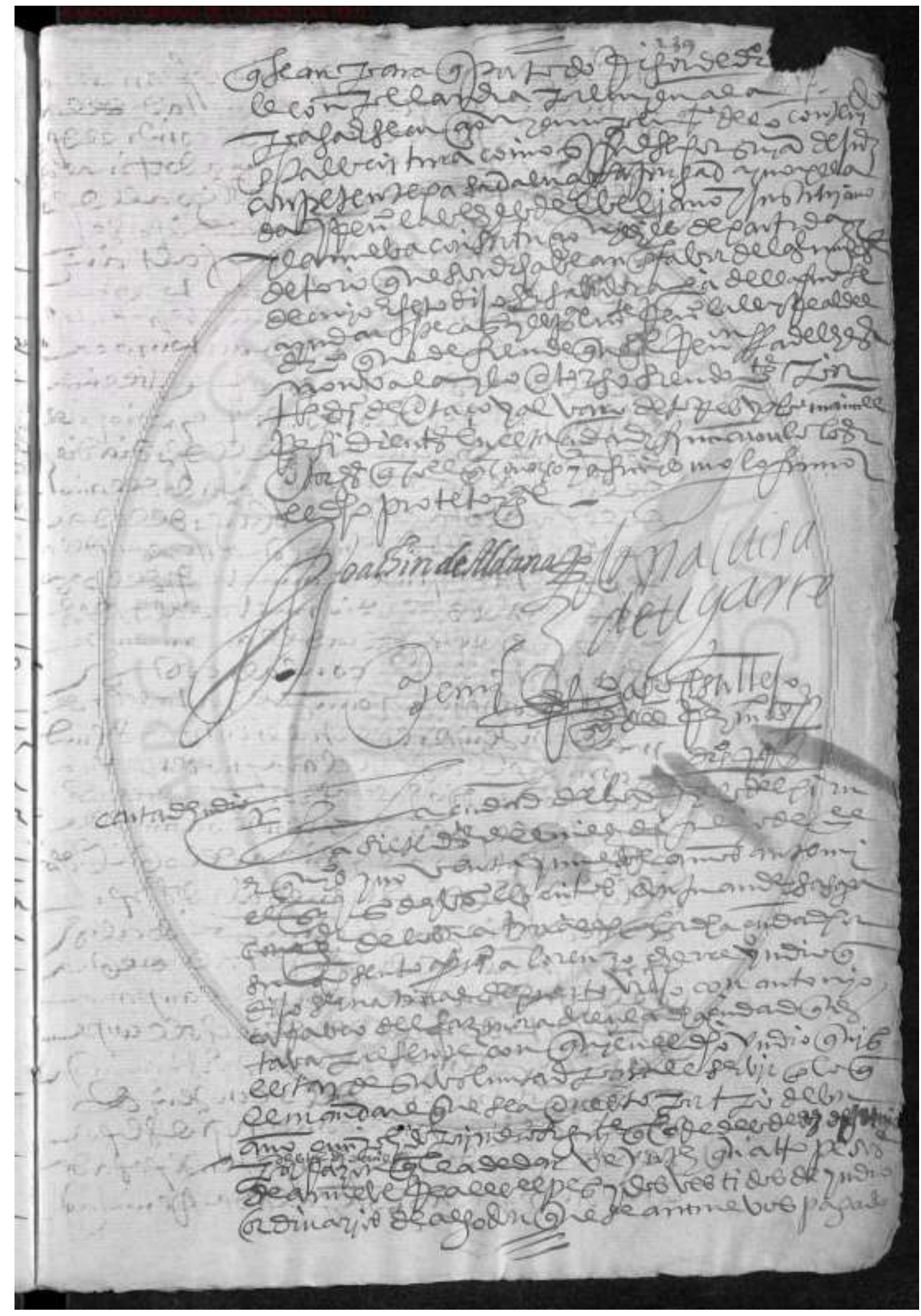

Fuente: Archivo General de la Nación del Perú, Signatura: N_1_RAC1_22,185_239-240_0610. 
DOCUMENTO 12.- CARTA DE DOTE Y ARRAS DE DOÑA JUANA DE SOlóRZANO, NATURAL DE LA Ciudad de Puerto Viejo, con Domingo Martín, natural de Villanueva del Algarbe EN LOS REINOS DE PORTUGAL Y RESIDENTE EN LIMA, EN LA QUE SE LE TRANSFIERE Y CEDE EN POSESIÓN AL FUTURO ESPOSO LA CANTIDAD Y CONCEPTO DE 2000 PESOS DE PLATA DE A NUEVE REALES EL PESO (Lima, Virreinato del Perú 25.04.1601).

${ }^{42}$ Carta de Dote.- Sepan quantos esta carta vieren como yo, Domyngo Martín natural de Villanueva del Algarve de Portugal, hijo ligítimo de Diego Rodríguez y de Beatriz Rodríguez su muger, resydente que soy en esta Çiudad de los Reyes del Pirú, otorgo y conozco que resçibo en dote caudal y casamyento con Doña Juana de Solórzano, natural de la Çiudad de Puerto Viejo destas Yndias que está presente, hija de Joan de Santa Cruz. de Solórzano y de Marya Ruiz sus Padres, que la dicha su madre asy mismo está presente, un myll pesos de plata corriente de a nueve reales el peso que me a dado y entregado en Reales y los he recibido de la dicha Marya Ruiz, madre de la dicha my esposa, de los quales me doy por contento y entregado a my voluntad, sobre que renunçio la esebçion de la ynumerata pecunya y leyes de la entrega y prueva de la paga y mal engaño, como en ellas se contiene, y por onra de nuestro casamyento y acreçentamyento de la dicha dote de vos la dicha my esposa, otorgo que vos doy y prometo en arras protermiçiones, ${ }^{43}$ forma perfeta yrrevocable, donaçion quel derecho llama entre libros otrosy myll pesos de la dicha plata de a nueve rreales de mys propios bienes en los quales y deçima dél los que de presente tengo, confieso que bastantemente caben los dichos myll pesos corrientes, que juntos con la dicha dote que reçybo son dos myll pesos de a nueve reales el peso; y quyero, consiento, y es mi voluntad que luego e cada e quando acaezca porquel matrimonyo, se reparta de entre my y vos la dicha Doña Juana de Solórzano my esposa por muerte e por otro qualquyer caso en derecho permytido, que vos la dicha my esposa e la persona que por vos fuere parte, ayays y cobre y de my y de mys bienes, y de lo mejor portado dellos los dichos dos myll pesos corrientes de la dicha plata de nueve reales el peso de la dicha dote y arras, syn esperar la dilaçion del año quel derecho permite, porque desde ahora por tal entonzes yo renunçio la dicha dilaçion y el derecho que a ella concede, contra lo qual no yntentare remedio ny recurso alguno por nynguna causa ny en derecho que de my favor sea, y a la firmeza de lo susodicho, obligo mi personas e bienes avidos e por aver, y doy poder cumplydo a qualesquyer Juezes e Justiçias del Rey nuestro Señor de qualquyer fuero e jurisdiçion que sean, ante quyen esta causa fuere presentada y della pedido $/{ }^{44}$ cumplimyento de Justiçia, a cuyo fuero e jurisdiçion, me someto con la dicha my persona e bienes, y espeçialmente a las justiçias desta dicha Çiudad y Alcaldes de Corte que en ella resyden y renunçio my propio fuero, domycylyo e Vezindad que tengo e tuviere y ganare, y la ley sit convenerid de jurisdiçione onyun judicun y la Nueva Prematica de las sumysiones y otra que las dichas justiçias me conpelan e apremyen por todo rigor de derecho a la paga, e execuçión y cumplimyento de lo contenydo en esta escritura, como sy fuese por sentençia difinytiva de Juez competente y aquella por las partes fuese consentida en Juizio y pasada en cosa juzgada y no apelada; y renunçio qualesquyera leyes, fueros y derechos de my favor y defensa, espeçialmente la Ley Real del derecho que defiende que general renunciaçion, fecha de leyes non vala. " E yo la dicha Doña Joana de Solórzano, que a lo que dicho es, he sido y soy presente, otorgo que açeto en mi favor esta escritura, segund y como en ella/ ${ }^{45}$ se contiene, ques fecha y otorgada, estando en las Casas de la morada de la dicha María Ruiz, madre de la dicha Doña Juana de Solórzano desposada en la dicha Çiudad de los Reyes del Pirú, resydiendo en ella el Audiençia y Chançillerya Real de Su Magestad, año del nasçimyento de nuestro Salvador Jesucrysto, a veynte y çinco días del mes de Abril de myll y seisçientos y uno años. Y porque los dichos Domyngo Martín y Doña Juana de Solórzano su esposa, otorgantes dijeron no sabían escrivyr, firmó a su ruego uno de los testigos desta carta, siendo testigo el Lyçenciado Sebastián Gallegos Presbítero y Sebastián Martyn y Diego Martynes resydentes en esta dicha Çiudad, porque los otorgantes que firmaron los dichos testigos en forma de derecho, conozidos y ser los aquí contenydos, dijeron no sabían firmar, firmó uno de los testigos a su ruego. A ruego de ambos otorgantes (f) El Liçenciado Sebastián de Gallegos. Ante my; (f) Rodrigo Alonso Castillejo. Escrivano del Rey nuestro Señor.

Derechos 12 Reales. I

\footnotetext{
42 Archivo General de la Nación del Perú, Signatura: N_1_RAC1_22,662_864v-866_2077, Vuelta folio 854

${ }^{43}$ Archivo General de la Nación del Perú, Signatura: N_1_RAC1_22,662_864v-866_2078, Inicio folio 855.

${ }^{44}$ Archivo General de la Nación del Perú, Signatura: N_1_RAC1_22,662_864v-866_2079, Vuelta folio 855.

${ }^{45}$ Archivo General de la Nación del Perú, Signatura: N_1_RAC1_22,662_864v-866_2080, Inicio folio 856.
} 


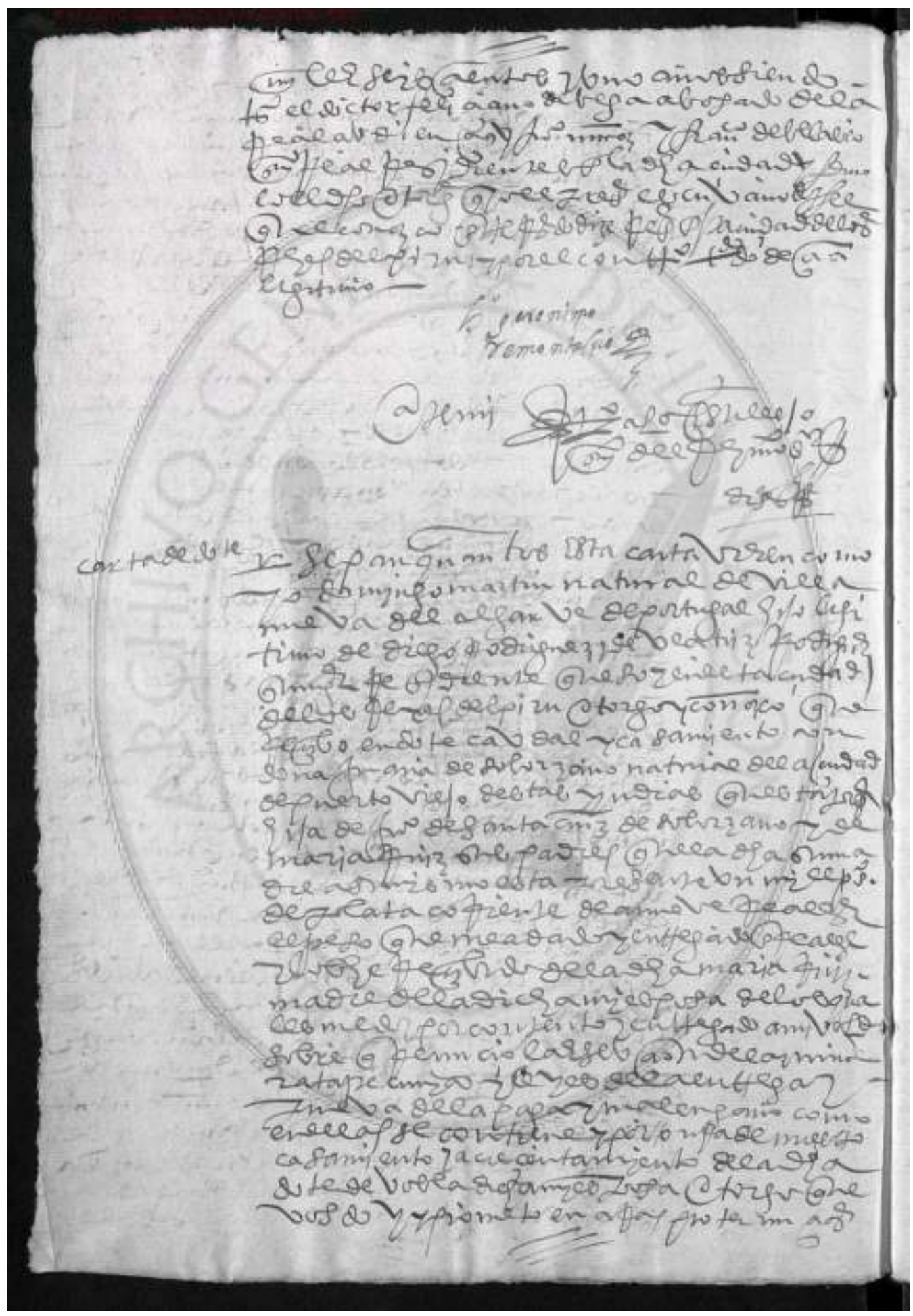

Fuente: Archivo General de la Nación del Perú, Signatura: N_1_RAC1_22,662_864v-866_2077, Vuelta folio 854. 


\section{Bibliografía}

AGN, A. G. (2018 ). Archivo General de la Nación del Perú. Recuperado el 19 de agosto de 2018. http://agn.gob.pe/portal/servicios/1522951689-consultas.

Arredondo. M. Recopilación de Albeyteria, sacada de varios autores. Editado por J. d. Valdés. Madrid, España, 1658.

Bellver Amaré, F. La creación de un mundo. Hispanoamérica. Madrid, España: Machado Grupo de Distribución, 2014.

Bennassar, B. La España del Siglo de Oro. Traducido por P. Bordonava. Barcelona, Cataluña, España: Editorial Crítica, 1983.

Garcés Garcés, J. A. Paleografía diplomática española y sus peculiaridades en América. Quito, Pichincha, Ecuador: Editorial Casa de la Cultura Ecuatoriana, 1960.

García Alcívar, J. J. Mecanismos básicos para investigar el patrimonio documental manuscrito en plataformas en línea. Instituto Nacional de Patrimonio Cultural. Portoviejo: Sistema de Gestión Documental Quipux, 2017.

Registros escribaniles de la Tenencia de Puerto Viejo, editado por E. F. Solorzano Zambrano. Portoviejo, Manabí, Ecuador: Amazon Kindle Publishing, 2017.

Gombrich, E. H. La Historia del Arte. Decimosexta edición. Londres, Reino Unido: Phaidon Press Limited, 2010.

Lozón Urueña, Ignacio. Madrid Capital y Corte. Usos, costumbres y mentalidades en el siglo XVII. Madrid: Consejería de Educación Comunidad de Madrid, 2004.

María Mercedes Ladrón de Guevara. Manual de Paleografía. Bogotá, Colombia: Centro Editorial Javeriano, 1996.

Octavio Latorre T. Thomás de Berlanga y de descubrimiento de Galápagos. Quito, Pichincha, Ecuador: Artes Gráficas Señal, Impreseñal Cía. Ltda., 1996. 